\title{
UN NUEVO SECTOR PRODUCTIVO EN EL ALFAR ROMANO DE CARTUJA (GRANADA): EL HORNO D4 Y SU TESTAR CERÁMICO
}

\author{
A NEW PRODUCTION AREA IN THE ROMAN POTTER'S WORKSHOP OF CARTUJA: THE D4 KILN \\ AND ITS DISCARDED CERAMIC
}

\author{
A. SANTIAGO MORENO PÉREZ* \\ afrades2@yahoo.es \\ http://orcid.org/0000-0003-4524-9558
}

ESTHER VILLARINO MARTÍNEZ

desthera@yahoo.es http://orcid.org/0000-0002-8886-2750

Recepción: 01-03-2017

Aceptación: 08-05-2017

\section{Resumen}

En el presente trabajo se analiza un testar cerámico emplazado en el interior del Horno D4, perteneciente a un nuevo sector productivo del alfar romano de Cartuja identificado en 2014. Los resultados han posibilitado ampliar el conocimiento del repertorio de cerámicas comunes del alfar, pero también realizar una primera aproximación a la actividad productiva de este sector de las inmediaciones de la Facultad de Teología, cuya instalación se originaría en plena época de apogeo del alfar con objeto de intensificar la producción.

Palabras clave. Cerámica común romana; alfar de Cartuja; sectores funcionales alfareros.

\begin{abstract}
This study analizes the discarded ceramic of the D4 kiln, discovered in 2014 and located in a new functional area in the Roman potter's workshop of Cartuja. The results have improved the knowledge of the common ceramic repertoire in the workshop, and has given a preliminary approach to the productive activity in this area close to the Faculty of Theology. This area was created when the workshop was at its peak in order to increase production.
\end{abstract}

Key words. Roman common repertoire; potter's workshop of Cartuja; functional workshop areas.

\footnotetext{
* Grupo de Investigación de la Junta de Andalucía HUM 296, «Arqueología de la época clásica y antigüedad tardía en Andalucía Oriental».
} 


\section{INTRODUCCIÓN}

El seguimiento arqueológico realizado entre 2013 y 2015 en el Campus Universitario de Cartuja, motivado por las obras de su proyecto de reurbanización ${ }^{1}$, ha ampliado las perspectivas de investigación del conocido alfar romano emplazado en este espacio del actual casco urbano de Granada. Con anterioridad a dicha intervención la zona conocida del alfar de Cartuja se emplazaba en la orilla meridional del río Beiro, a unos $1,7 \mathrm{~km}$ lineales al norte de la muralla septentrional de la ciudad iberorromana de Iliberri (Fig. 1), y su investigación se remonta a las campañas realizadas por M. Sotomayor entre 1964 y 1970 (Sotomayor, 1966; 1970; 1991), retomándose desde 1991 de la mano de la propia universidad como parte de distintos programas docentes (Casado et al., 1999; Fernández, 2004: 204-205). Esta zona, a la que se aludirá en adelante como «Sector del Beiro», aglutina, en unos $1.070 \mathrm{~m}^{2}$, un conjunto de estructuras correspondientes a distintas fases del proceso productivo, tales como espacios de trabajo, de preparación y almacenamiento de arcillas, canalizaciones de suministro hidráulico, puntos de vertidos, y un total de diez hornos (Hornos 1-10). Todo ello definía un complejo de envergadura, caracterizado por una amplia variedad de producciones destinadas, por lo conocido hasta ahora, al mercado regional (Fernández, 1992: 145; 2013: 133), con una cronología general situada entre el s. I y mediados del s. II d.C. (Sotomayor, 1970; 1991; Serrano, 1975; 1979; 1981; 1999: 140-141; Casado et al., 1999; Fernández, 2004: 204-214; 2013: 132-133; 2015: 254-255).

La intervención de 2013-2015 ha supuesto una nueva valoración de la organización y topografía del complejo, con la identificación de nuevos sectores productivos lo suficientemente distanciados como para plantear un modelo de alfar suburbano de organización diseminada, que se extendía al menos en unas 17 hectáreas por la mayor parte del actual campus universitario (Moreno y Orfila, 2017). El contexto que analizamos en este trabajo se encuadra en uno de estos nuevos sectores, recientemente denominado «Sector de Teología», identificado al abrir una serie de
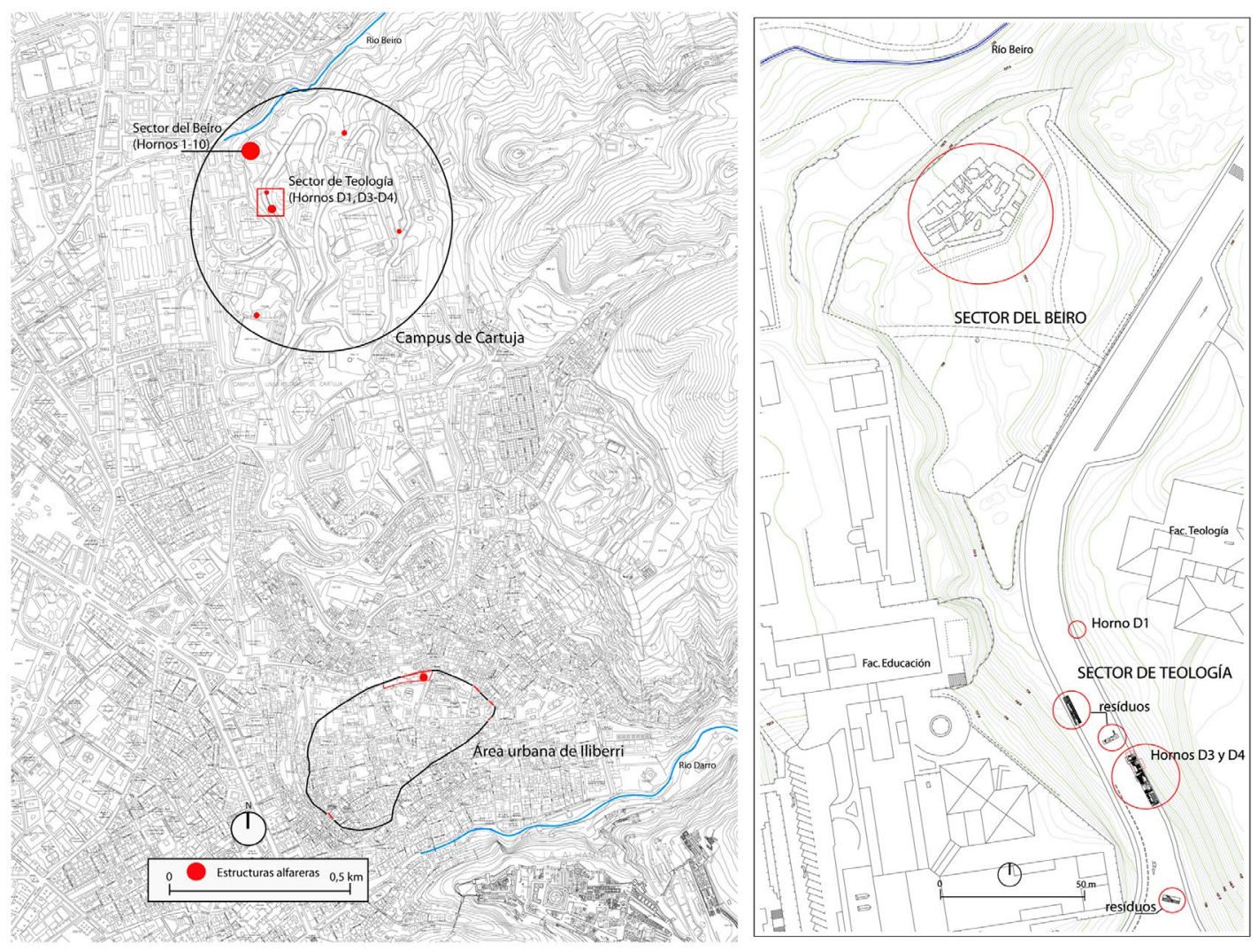

Figura 1: Localización del alfar (izquierda), y de los sectores del Beiro y Teología (derecha), con señalización de los contextos excavados en 2014 en este último.

1. La documentación presentada en este trabajo procede la Intervención Arqueológica Preventiva, exp.6014 de la Consejería de Cultura de la Junta de Andalucía, financiada por la Universidad de Granada. Con una duración de dos años, fue dirigida en su primera fase (agosto de 2013-agosto de 2014) por Guillermo García-Contreras, y en la segunda (septiembre 2014-julio 2015), por A. S. Moreno Pérez. El desarrollo de la misma contó con el asesoramiento científico del Departamento de Historia Medieval y CC. Y TT. Historiográficas de la Universidad de Granada, a través del profesor A. Malpica Cuello, y del Departamento de Prehistoria y Arqueología de esta misma universidad a través de la profesora Margarita Orfila Pons. 
zanjas para acometidas bajo el tramo de la calle Prof. Vicente Callao situado entre las Facultades de Educación y Teología, a unos $150 \mathrm{~m}$ de media al sur de las estructuras excavadas junto al Beiro (Fig. 1). Del sector se han documentado una serie de niveles sedimentarios con residuos de la producción, localizados en dos pequeños sondeos, y un yacimiento parcialmente excavado integrado por dos hornos dispuestos en batería, los Hornos D3 y D4, e inmediatamente al sur un área de servicio delimitada por un muro (Moreno y Orfila, 2017). Al mismo sector corresponde también el denominado Horno D1, testimoniado por Sotomayor en 1971 (Sotomayor, 1991; Fernández García, 2004: 204-208), pues éste se localiza a tan solo unos $48 \mathrm{~m}$ al norte de los nuevos D3 y D4 (Fig. 1), con los que guardan además estrecha relación en cuanto a su emplazamiento, orientación y tipología.

En el presente trabajo se plantea una primera aproximación a la producción cerámica en este sector a través del análisis de un amplio vertido cerámico efectuado en el interior del Horno D4 como parte de su proceso de amortización, el cual constituye el contexto artefactual cuantitativa y cualitativamente más importante de los excavados en el Sector de Teología. Se analiza, por tanto, un contexto específico de la producción de Cartuja, centro donde se fabricaron vajillas comunes, engobadas, TSH, material de construcción, e incluso determinados elementos artesanales.

El análisis de esta variada producción formó parte de los primeros programas de investigación del yacimiento, inicialmente clasificada por M. Sotomayor (1966) y sistematizada por E. Serrano en su tesis doctoral (Serrano, 1974). Esta última autora distribuyó la vajilla en cuatro grupos: cerámicas de importación no producidas en el centro (Serrano, 1975; 1981); TSH, incluyendo hasta seis formas propias del alfar (Serrano, 1975; 1979); cerámica común, clasificada en base a grupos funcionales (Serrano, 1975; 1978); y cerámicas engobadas que por su especial tratamiento, «entre la sigillata hispánica y la común», pasó a denominar inicialmente «Granatensis» (Serrano, 1975: 220-226). Posteriormente se suprimió el término «Granatensis», que implicaba así mismo posibles tanteos para obtener el barniz característico de la sigillata, pasando a definirse como cerámicas engobadas, cuya especial caracterización constituye un capítulo independiente de la producción local de Cartuja (Serrano, 1999: 139-140; Fernández, 2004: 210; Fernández y Ruiz, 2005: 151). Esta sistematización ha constituido la base sobre la cual se han realizado posteriores revisiones (Casado et al., 1999; Fernández, 2004), entre las que destacamos la discriminación de las producciones de cerámica común de cocina en función de sus pastas (Casado et al., 1999), y la continuidad de los avances en el análisis de la TSH (Serrano, 1999; Fernández, 2004: 211-214; 2013: 132-133; 2015: 253-254, 282283; Fernández y Ruiz, 2005: 150-153; Compaña et al., 2010).

\section{EL HORNO D4 Y SU VERTIDO CERÁMICO DE AMORTIZACIÓN}

El área donde se localizaron los Hornos D3 y D4, de la que se intervino un espacio longitudinal de unos 57 $\mathrm{m}^{2}$ de superficie, se vio alterada por la instalación en los años setenta de una línea de abastecimiento cuya fosa longitudinal $(0,80 / 90 \mathrm{~m}$ de potencia, y $0,68 / 76 \mathrm{~m}$ de anchura) atravesaba todo el yacimiento de norte a sur cortando parte de sus estructuras y niveles sedimentarios (Fig. 3). Las actuaciones autorizadas por la Delegación de Cultura de Granada fueron, no obstante, muy limitadas, y se centraron precisamente en el área afectada por la mencionada fosa, con el fin de evaluar parcialmente el registro y su estado de conservación ${ }^{2}$. En el caso del Horno D4, la excavación se limitó a la zona central de su cámara de cocción, y en concreto, tras el vaciado de los rellenos de la acometida de los años setenta, se llegó a excavar hasta la parrilla la totalidad de su anchura en un espacio longitudinal de 1,50 $\mathrm{m}$ de ancho. Las características de la caldera, registradas de modo aproximado a partir de los orificios y fracturas de la parrilla, definen una cámara rectangular distribuida por una serie de muros paralelos intensamente vitrificados que configuran a su vez una doble galería de arcos de medio punto, de unos $0,86 \mathrm{~m}$ de anchura, y una altura que superaría los $0,90 \mathrm{~m}$. La anchura total del interior del laboratorio, coincidente con la de la caldera, es de 3,44 m, mientras la longitud E-O debía aproximarse a los 4,40 $\mathrm{m}$ (Fig. 2) en función del número y la anchura de los muros transversales de la caldera, y el punto donde se localiza hacia el oeste el cierre hacia el praefurnium del Horno D3, que debía coincidir con el del D4 (Moreno y Orfila, 2017). Los muros que delimitan el laboratorio conservan hasta $1,20 \mathrm{~m}$ de altura, y disponen en su cara interna un paramento de adobes de 0,10/12 m de grosor que debían configurar el alzado y la totalidad de la bóveda de la cámara (Fig. 5). La parrilla tiene $0,10 \mathrm{~m}$ de grosor y está constituida por ladrillos de adobe dispuestos de canto, configurando hileras dobles de orificios de 0,10/14 m de diámetro. Una capa de revestimiento de arcilla, de la que se ha documentado hasta tres remodelaciones, se extiende sobre la superficie de la parrilla y la cara interna de los alzados de adobes, sellando toda la cámara de cocción. Hornos de estas características, cuadrangulares con doble galería arqueada, se encuadran en el tipo IIc o IId de la clasificación de Cuomo di Caprio (2007), A5 de J. Coll (2008), o 2.2 de Sotomayor (1997), y se han documentado en los ejemplares $n^{\circ} 1$ y 3 del sector

2. La prioridad de la intervención en este yacimiento fue su evaluación preliminar $\mathrm{y}$, por consenso de todos los implicados en la obra, el desvío de las infraestructuras planificadas en este espacio, y el diseño de un sistema de protección y cubrición específico que garantizase su conservación para futuras investigaciones. 


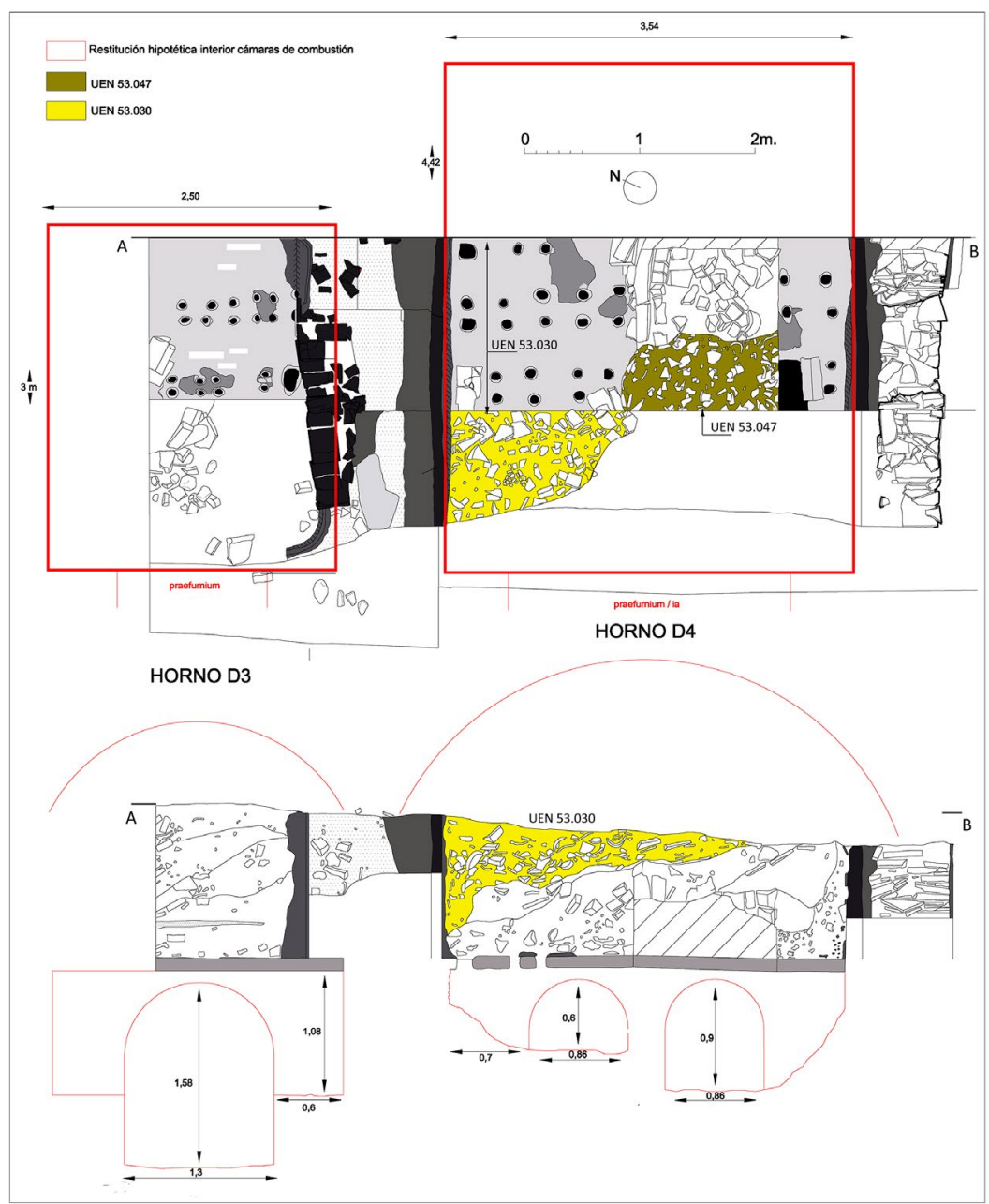

Figura 2: Planta final y Perfil Este del tramo excavado de los Hornos D3 y D4, con restitución de sus dimensiones. Se indica la posición de los dos estratos integrantes del testar.

excavado a orillas del Beiro, pertenecientes a la fase de apogeo de la producción, y en el cercano Horno D1, cuyas dimensiones $(4,10 \mathrm{~m}$ de anchura) son precisamente las más próximas al que nos ocupa.

La producción específica a la que se destinó el horno es indeterminada, y no se le puede asociar el material cerámico hallado en su interior, pues este corresponde en su totalidad a vertidos realizados sobre los derrumbes de su bóveda, efectuados, por tanto, tras el colapso del horno. En este sentido, esta tipología de hornos se ha relacionado con la cocción de material de construcción cerámico (Bermúdez 1982-83: 223-225), y esta misma observación fue planteada por M. Sotomayor a propósito de los otros tres hornos cuadrangulares con doble galería identificados hasta ahora en Cartuja (Hornos 1, 3, y D1: Sotomayor 1970: 715; 1990). No obstante, y pese a que el material latericio está bien representado en el Sector de Teología, no existe documentación que permita avalar una destinación tan específica para el Horno D4, resultando también posible que cociera distintos productos cerámicos en función de las necesidades productivas del alfar.

El colapso del horno está evidenciado en los derrumbes de adobes pertenecientes al alzado y bóveda del laboratorio caídos directamente sobre la parrilla, los cuales adquieren una potencia máxima de $1,02 \mathrm{~m}$ hacia el centro de la cámara, buzando desde allí hacia los laterales de la misma. Tras su colapso el horno es amortizado como receptor de una serie de vertidos cerámicos. El primero de ellos es un vertido de grandes fragmentos de tegulae efectuado sobre el derrumbe de adobes, aunque restringido a la zona noreste del interior del laboratorio (UEN 53.073) y con una potencia que no supera los $0,32 \mathrm{~m}$. Sobre este estrato inicial, y sobre el resto de derrumbes de adobes, se realizó un amplio vertido cerámico del que se han individualizado dos estratos principales: UEN 53.047, que se extiende por la caldera, y UEN 53.030, que ocupa parte del laboratorio. La posición en el interior del horno de ambos estratos y su diferente matriz sedimentaria ${ }^{3}$ justificó la

3. 53.030 presenta una matriz de tierras orgánicas sin compactar, de color marrón y con cierto componente de áridos, aunque tenía algunas bolsadas grisáceas en los puntos de mayor concentración de materiales. Por su parte, la unidad 53.047 estaba integrada por un sedimento orgánico un tanto limoso de color gris. 

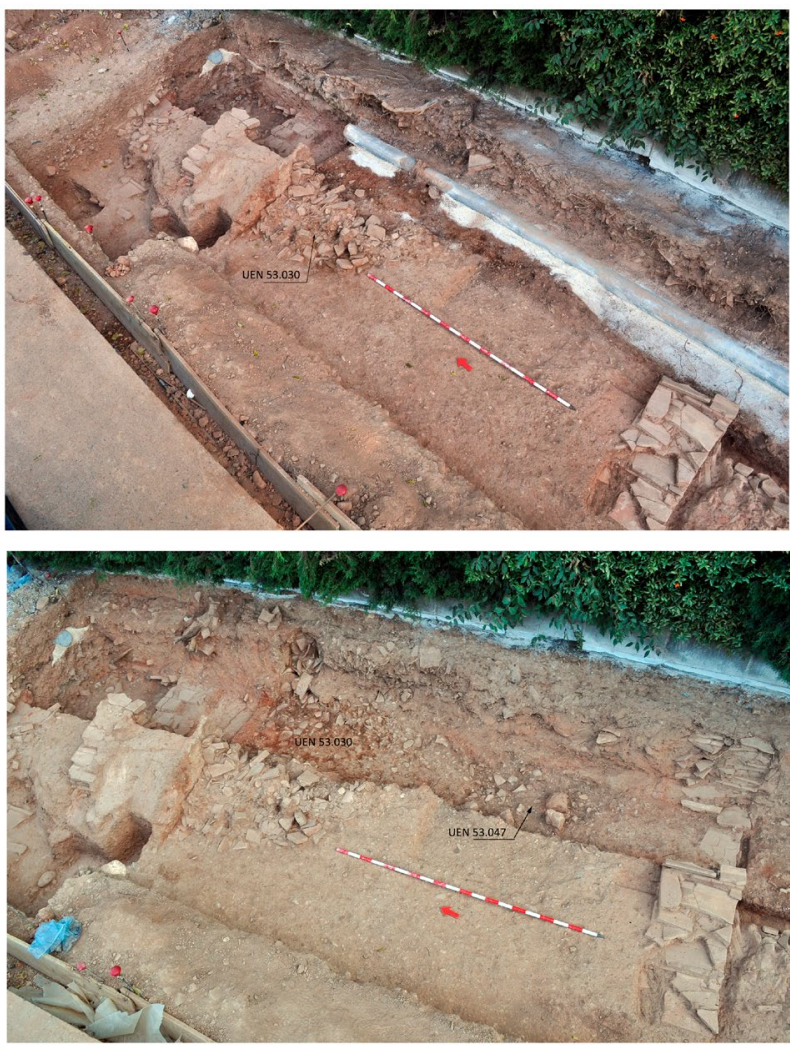

Figura 3: Proceso de excavación del Horno D4. Imagen superior: acometida de los años setenta cortando los niveles del horno, entre ellos el estrato 53.030. Imagen inferior: los estratos 53.030 y 53.047 en contacto, una vez vaciados los rellenos de la mencionada acometida.

individualización de los mismos, aunque los dos presentaban un contacto físico hacia la parte central del laboratorio. No obstante, esta zona de contacto había sido parcialmente eliminada en el área intervenida por la fosa para acometida hidráulica de los setenta, y solo se pudo documentar un pequeño tramo bajo los rellenos de dicha acometida (Figs. 3 y 4), extendiéndose de modo indeterminado hacia el oeste de la zona excavada. Por tanto, desde una perspectiva estratigráfica ambos corresponden a un mismo episodio continuado de vertidos procedentes de desechos de la producción realizada en el sector, aunque ajenos a la producción específica del Horno D4. La alta densidad de materiales; la reiteración de un número limitado de tipos cerámicos, en ocasiones concentrados en determinados puntos; y la presencia de fallos de cocción, principalmente deformaciones, estallidos y engobes pasados de cocción, nos han llevado a definir estos vertidos como un testar cerámico.

Dejando de lado el pequeño vertido inicial de tegulae atrás aludido, la secuencia del testar integrado por las unidades 53.030 y 53.047 se inicia con la apertura de una cavidad sobre los derrumbes de adobes y la parrilla hacia la zona centro-occidental del horno. Las dimensiones de esta cavidad son desconocidas, pues se introduce en el perfil oeste de la excavación en dirección al/los praefurnia, documentándose en el área intervenida una extensión en planta de 1,60 x 0,87 m. El estrato
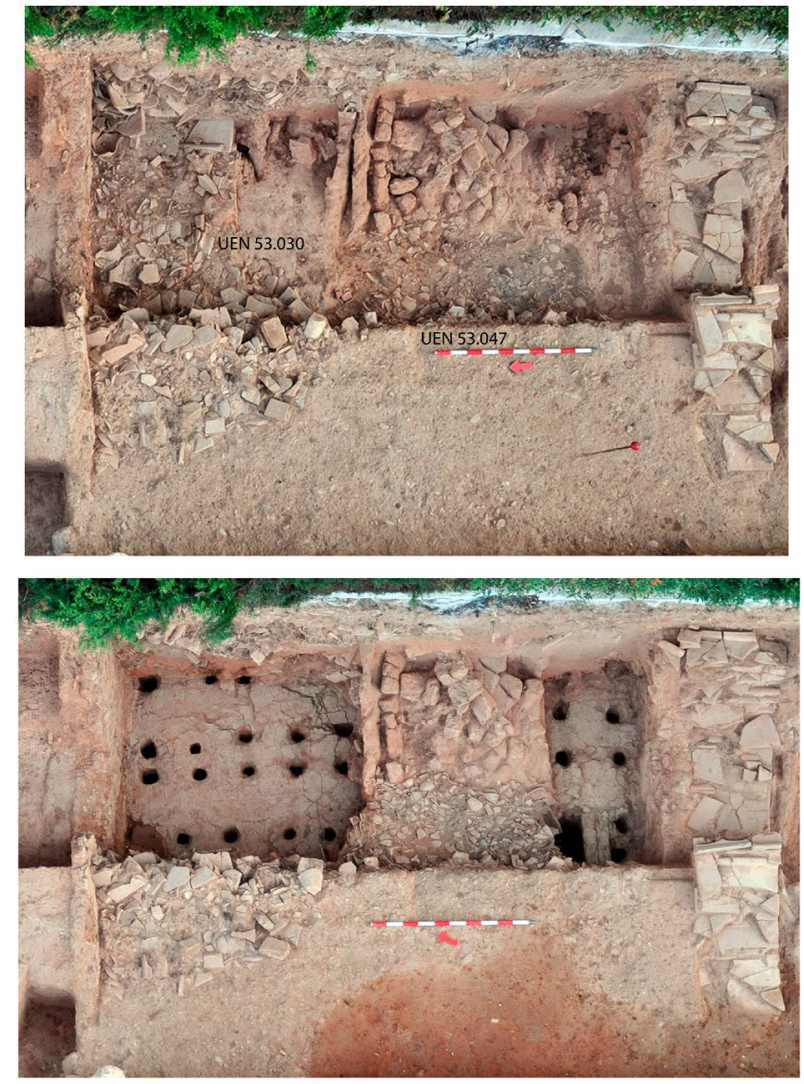

Figura 4: Proceso de excavación del Horno D4. Imagen superior: posición de los estratos 53.030 y 53.047 sobre los derrumbes de adobes del laboratorio. Imagen inferior: estado final de la intervención.

53.047 se introduce aquí ocupando buena parte de la caldera, especialmente de la galería meridional ${ }^{4}$, y rebosa ligeramente la cavidad realizada en la parrilla y derrumbes. Del estrato se excavó tan solo un pequeño punto de $0,44 \times 0,26 \mathrm{~m}$ correspondiente a su extremo SE, profundizándose en el mismo unos $0,30 \mathrm{~m}$, únicamente

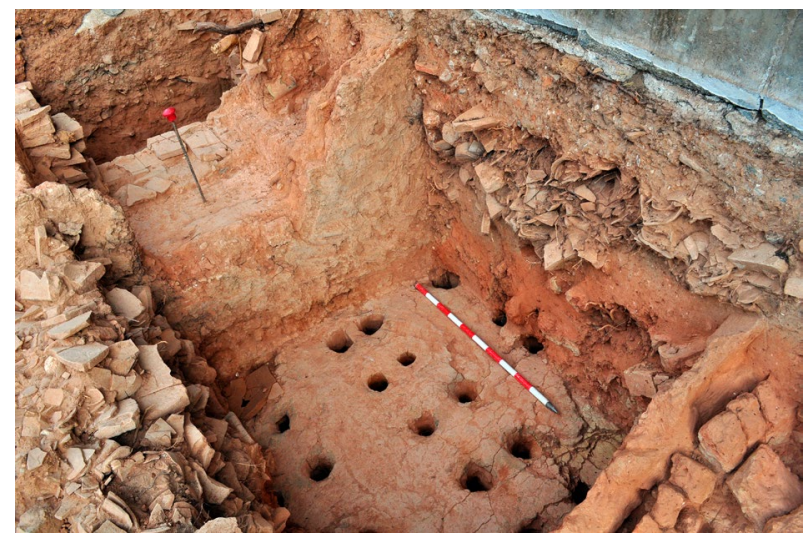

Figura 5. Vista de la parrilla y el alzado de adobes repellados del muro norte del laboratorio. Se aprecia en los perfiles este y oeste la continuidad del estrato 53.030 .

4. Desde los orificios de la parrilla se observó la alta concentración de vajilla fragmentaria al fondo de dicho pasillo. 

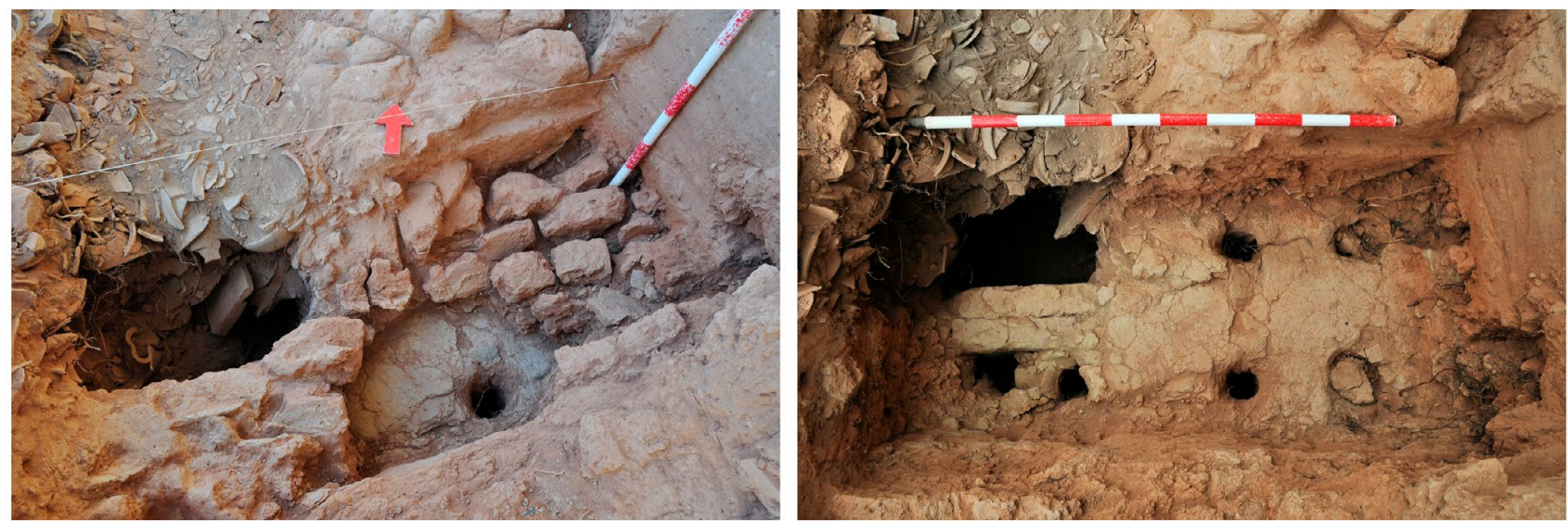

Figura 6: Excavación del estrato 53.047 en la zona sur del laboratorio. Imagen izquierda: punto excavado de la cavidad practicada sobre los derrumbes de adobes y parrilla, donde se introduce, hasta el fondo de la galería sur, el estrato 53.047. Imagen derecha: detalle de la parrilla y la parte de la fractura realizada para realizar el vertido 53.047.
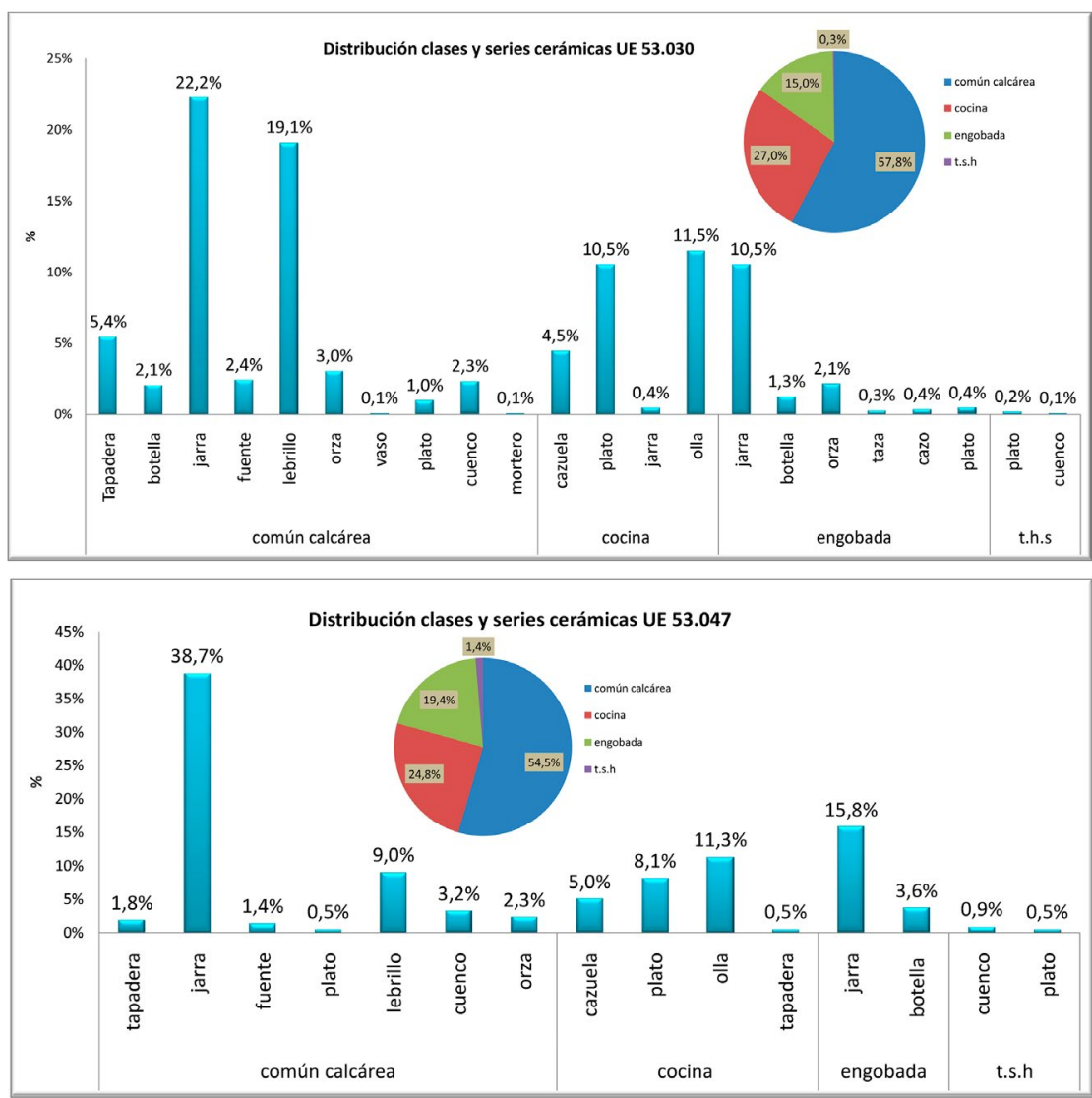

Figura 7: Desglose por unidades del porcentaje de clases (gráfico circular) y series cerámicas del testar, tomado a partir del N.m.I.

lo suficiente para documentar la fractura de la parrilla (Fig. 6). Pese a esta limitación, se recuperaron un total de 1.753 fragmentos cerámicos concentrados, lo que da una idea de la densidad artefactual del estrato. Por su parte, el estrato 53.030 rellena buena parte de la mitad norte del laboratorio, localizándose su punto más potente $(1,06 \mathrm{~m})$ contra el alzado norte de la cámara, desde donde buza considerablemente hacia el centro del horno, punto donde se establecía el contacto físico sobre el techo de la unidad 53.047. La posición del vertido indica que éste se realizó inmediatamente sobre el anterior, en el espacio central del laboratorio, ultimándose contra la pared norte del mismo, donde se superpone al vertido de tegulae 53.073, y donde alcanza su cota máxima. Pese a que solo se excavó una parte del estrato, pues este se extendía más allá de la zona intervenida y gran parte de ésta estaba ocupada por los rellenos de la acometida de los setenta, el volumen intervenido fue mayor que en el caso del estrato anterior, ascendiendo a 8.459 la cuantificación total de fragmentos cerámicos recuperados. 
Pese a la gran diferencia en cuanto al volumen de materiales recogidos, la homogeneidad de la composición de ambos estratos que se refleja en los gráficos de la figura 7, especialmente en cuanto a clases y series cerámicas, corrobora desde otra perspectiva que el vertido pertenece a un mismo episodio más o menos dilatado en el tiempo, aunque en cualquier caso perteneciente a la misma fase de producción.

\section{CLASIFICACIÓN DEL CONJUNTO CERÁ- MICO Y METODOLOGÍA}

El análisis cerámico se efectuará unificando ambos estratos, 53.030 y 53.047, que, como se ha señalado, pertenecen a un mismo episodio continuado de vertidos, tal y como confirman también las equivalencias de su composición. Un problema fundamental para el análisis de este conjunto es el desconocimiento de su grado de representatividad respecto a la totalidad del vertido, pues como se ha señalado solo se excavó una parte del mismo. No obstante, debe tenerse en cuenta que el repertorio artefactual recuperado no se ve sustancialmente alterado en ninguno de los estratos excavados en el yacimiento, incluyendo la ingente cantidad de materiales recogidos en los rellenos de la fosa reciente, la mayor parte de los cuales debía proceder de la alteración del testar. Por ello, debe considerarse un análisis forzosamente preliminar, aunque aplicado a una muestra procedente del contexto artefactual más importante y representativo del sector.

El conjunto del vertido está integrado casi exclusivamente por vajilla, resultando residuales los materiales de construcción cerámicos $(0,53 \%$ del contexto excavado), así como la categoría de cerámicas finas, representadas en Cartuja por la TSH (0,34\%), con lo que el 99,13\% del material corresponde a las cerámicas comunes, categoría que centrará el análisis del presente trabajo.

Ante los diversos criterios de clasificación hasta ahora desarrollados, y teniendo en cuenta la limitación de tipos respecto a la amplia variedad de cerámicas comunes atestiguadas en Cartuja, así como las novedades que ofrece el vertido respecto a la producción del alfar, se ha optado por realizar una clasificación exclusivamente destinada a analizar el contexto específico que presentamos. Tal clasificación, que parte de la investigación italiana (Olcese, 2003: 19-23; Cortese, 2005: 326-330) y que ha sido adoptada también para las producciones comunes de alfares béticos como el de Andújar (Peinado, 2010; 2013a; 2013b), toma determinados aspectos tecnológicos, fundamentalmente las pastas, como base taxonómica para el establecimiento de clases cerámicas. Aunque para la caracterización de las pastas del vertido se ha realizado únicamente un análisis macroscópico ${ }^{5}$, éste ha sido suficiente para definir a grandes rasgos las tres clases

5. Análisis realizado con lupa de aumento de $75 \mathrm{~mm}$. de cerámicas comunes identificadas en el vertido: la cerámica de cocina, la común calcárea, y la engobada.

Específicamente destinada a la cocción de alimentos, la cerámica de cocina está realizada con una pasta apta para la exposición al fuego y soportar el choque térmico, por lo que se emplean normalmente pastas silíceas y porosas que dan lugar a características fácilmente identificables a nivel macroscópico, como son: la totalidad, del marrón y rojo al negro, y la presencia de vacuolas que aportan resistencia ante los procesos de dilatación - contracción (Olcese, 2003: 19-20; Cuomo di Caprio, 2007: 128; Peinado, 2013b: 271). La producción documentada en el vertido fue cocida exclusivamente en ambientes predominantemente oxidantes, sin que se hayan localizado producciones específicas cocidas en ambientes reductores como las analizadas, por ejemplo, en Andújar (Peinado, 2010: 151; 2013c), dando lugar a tonalidades que oscilan entre el rojo-anaranjado más o menos saturado y los marrones, aunque en algunos casos se obtienen pastas tipo sándwich con interiores grisáceos y exteriores anaranjados. En términos generales se trata de pastas de apariencia grosera y rugosa, con alta concentración de desgrasantes de mica y caliza ${ }^{6}$, generalmente de $0,5 / 1 \mathrm{~mm}$ con algunas inclusiones aisladas de unos $3 \mathrm{~mm}$, tanto de morfología redondeada como angulosa, en este último caso las de mayor tamaño.

La clase común calcárea se destina fundamentalmente a la vajilla de almacenamiento, preparación y consumo de alimentos, y se caracteriza tecnológicamente por el empleo de pastas calcáreas y poco porosas, aptas para resistir el choque mecánico, que dan lugar a cerámicas de aspecto compacto y tonalidades beige (Olcese, 2003: 19-10; Peinado, 2010: 129-131; 2013a). El material calcáreo recuperado en el vertido presenta una gama cromática que oscila entre el beige y el amarillento en la mayor parte de las piezas, y el rosado en algunos ejemplares, documentándose asimismo pastas que combinan tonos rosados en el núcleo cerámico y beige en la superficie. Muestran una baja densidad de desgrasantes de mica y caliza de grano fino (inferior a 1,5 mm), los primeros de tendencia alargada y los segundos generalmente redondeados.

Por último, la cerámica engobada, destinada fundamentalmente a la producción de vajilla de mesa y, secundariamente, almacenamiento, es quizás la clase más controvertida desde la perspectiva de su clasificación entre las cerámicas comunes, situación que, como se ha señalada en la introducción, ha quedado reflejada en la historiografía del alfar. En este sentido, el tratamiento cuidado, los grosores en ocasiones extremadamente reducidos, o la aplicación de engobe y en ciertos modelos decoración impresa, aproximan

6. El análisis macroscópico, parece indicar, además, la posible presencia de desgrasantes de cuarzo de grano muy fino, que dotaría a estas piezas de un componente más para soportar las altas temperaturas debido a su carácter refractario. 
estas producciones a la categoría de cerámicas finas. Sin embargo, el hecho de que diversos modelos imiten formas del repertorio de terra sigillata implica unas connotaciones de calidad, coste de producción, y accesibilidad por parte de la población que permiten definirlas como cerámicas comunes. Además, otro factor discriminatorio seria el hecho de que la mayor parte de los tipos cerámicos de esta clase no se produjeron en cerámica común calcárea, constituyendo unas producciones estandarizadas y de acusado carácter local. Tecnológicamente, su discriminación como una clase cerámica independiente dentro de la categoría de las comunes no viene exclusivamente señalada por la aplicación de los característicos engobes, ya que, como es sabido, algunas vajillas calcáreas de Cartuja presentan igualmente un acabado engobado. La discriminación se apoya fundamentalmente en las pastas que, aunque también calcáreas, muestran un grado de depuración mayor que permite tornear grosores en ocasiones muy reducidos, que pueden llegar a los $0,2 \mathrm{~cm}$. Analizadas recientemente desde una perspectiva arqueométrica (Compaña et al., 2010), las engobadas de Cartuja muestran también suficientes diferencias tecnológicas respecto a la producción local de TSH, aspecto que apoya igualmente la clasificación que aquí se propone.

Tras la clase, el siguiente nivel de clasificación aúna aspectos funcionales y morfológicos configurando agrupaciones en series cerámicas, las cuales tratan de definir a grandes rasgos aspectos utilitarios. Por último, dentro de cada serie se han discriminado distintos modelos, o tipos, y sus variantes en función de aspectos morfológicos relevantes ${ }^{7}$. El estudio morfométrico de series y tipos cerámicos se ha realizado sobre materiales que no presentaban alteraciones morfológicas producidas por cocciones defectuosas, quedando fuera de los objetivos del presente trabajo el análisis de estos fallos de cocción.

En la composición del vertido se han identificado nuevos tipos y variantes, aunque el grueso del material resultaba ya conocido a nivel tipológico. Es por ello que, para evitar reiteraciones, se omitirán descripciones del material ya conocido, remitiendo a los estudios correspondientes, resultando muy prácticos para el caso que nos ocupa los de E. Serrano $(1975 ; 1978)$. Con idéntico objetivo se ha restringido la presentación del aparato gráfico, limitado a los nuevos tipos y a matizar determinados aspectos de otros ya conocidos.

Una vez agrupados los materiales se buscaron familias de fragmentos (Orton et al., 1997: 71) con objeto de reconstruir las vasijas y obtener identificaciones morfológicas más completas, así como una correcta cuantificación de individuos. La cuantificación del material se ha realizado mediante el cálculo del número mínimo de individuos, en adelante N.m.I (Orton et al., 1997: 191-196), que consideramos el referente de

7. Para una descripción general de las formas cerámicas véase: Balfet et al., 1983. estimación más cercano a la realidad del conjunto. El N.m.I se ha calculado partiendo de la cuantificación de los bordes y las bases, siendo el más cuantioso de estos grupos el indicador seleccionado. Con objeto de obtener un mayor grado de concreción se ha calculado el número mínimo tipológico (N.m.T) que, aplicado a los tipos, cuantificaría los individuos completos más el número mayor entre bordes y fondos, más uno (Py y Adroher, 1991: 92; Peinado, 2010: 76). Estos datos se han recogido en una tabla de Microsoft Excel 2007, base de datos de la que parte el análisis estadístico que presentamos expresado en gráficos de barras.

\section{COMPOSICIÓN DEL VERTIDO}

El material de construcción constituye únicamente un $0,53 \%$ del conjunto recuperado $(0,28 \%$ en UEN 53.047 y $0,58 \%$ en UEN 53.030 . Imbrices $61 \%$; tegulae: $22 \%$, ladrillos: $17 \%$ ), y se encuentra en un estado muy fragmentario, por lo que incluso podría haber sido reutilizado en los procesos de cocción $^{8}$. Por su parte la TSH alcanza tan solo el $0,34 \%$ del conjunto, identificándose por N.m.I, dos cuencos de la forma 27 , tres platos de la forma $15 / 17$, y un pequeño fragmento muy deteriorado de cuenco con decoración a molde, probablemente de la forma 37. Por tanto, como se ha señalado anteriormente, el vertido está integrado mayoritariamente por tres clases de cerámicas comunes, cuyas series y tipos representados se estudian en este apartado. Aunque el análisis morfométrico, incluyendo los dibujos técnicos que se adjuntan, se ha realizado sobre fragmentos sin alteraciones morfológicas, se indicará cuando sea posible la incidencia de determinados defectos de cocción en las series y tipos cerámicos recogidos.

\subsection{CERÁMICA COMÚN CALCÁREA}

La cerámica común calcárea es la clase más abundante en ambos estratos, alcanzando un porcentaje del $58,53 \%$ de todo el conjunto. Se han identificado 9 series y hasta 23 tipos cerámicos, con una cuantificación a partir del N.m.T. expresada en la figura 8.

Jarra. Las jarras comunes calcáreas, con dos tipos genéricos y hasta siete variantes documentadas, es la serie más abundante de la clase cerámica con 335 individuos identificados $(48,8 \%$ de las comunes calcáreas), y también del conjunto del testar (24,96\%), incluyendo las distintas clases cerámicas registradas. Excepto una de las variantes (Tipo 1b), la mayor parte del material había sido clasificado con anterioridad,

8. Tal vez en el apilado de piezas, o como elementos auxiliares, al modo del fragmento de tegula que obturaba dos de los orificios de la parrilla del Horno D4 (Moreno y Orfila, 2017). 
aunque la alta cuantificación de la serie ha permitido profundizar en el conocimiento de la morfología de algunos tipos.

Tipo 1. En el tipo se incluyen distintas variantes cuyo denominador común sería la presencia de un solo asa, boca ancha y cuello escasamente diferenciado del cuerpo. Las jarras comunes de este tipo, especialmente las Tipo 1a, fueron depositadas masivamente en el vertido, por lo que debido a la abundancia de fragmentos se ha podido observar una especial incidencia de deformaciones y estallidos producidos durante el proceso de cocción como fallo más frecuente.

Tipo 1a. Corresponde a las «jarras de un asa con boca ancha y cuello poco marcado» de la clasificación de Serrano (1978: 252, $\mathrm{n}^{\mathrm{o}} 72$ ), y con sus 255 individuos identificados, constituye la variante de jarras más abundante, y por extensión, el tipo de vajilla más frecuente en todo el testar excavado. Característico de estas jarras de perfil piriforme es su borde exvasado, en el testar con diámetros comprendidos entre 14/15,8 $\mathrm{cm}$, y con una acanaladura más o menos pronunciada en la parte superior del labio (Fig. 9, 1-3). El asa arranca directamente desde el borde, lo que parece invalidar la posibilidad del uso de la acanaladura como asiento de tapadera, excepto en un $2 \%$ de los ejemplares donde el asa arranca inmediatamente por debajo del borde (Fig. 9, 3). Aunque ninguno de los individuos se ha conservado completo, es posible que la base de la jarra corresponda a los abundantes ejemplares cóncavos, en umbo, presentes en el testar, ya que éstos presentan concordancia en cuanto a grosor y diámetro (Fig. 9, 8). De aceptarse esta restitución la altura de estas jarras se situaría en torno a los $30 / 35 \mathrm{~cm}$ y unos $24 \mathrm{~cm}$ de diámetro en la panza. Se trata de una jarra de amplio desarrollo occidental en época altoimperial, atestiguándose su producción en centros laciales como Roma o Sutri fundamentalmente en el s. I d.C. (Olcese, 2003: 93, tav. 25, 7). Ampliamente atestiguado en la Bética, se registra su producción tanto en el Bajo Guadalquivir (García et al., 2013: 283, fig. 26, 8), como en la Alta Andalucía, resultando el tipo de jarra más abundantemente producida en Andújar hasta el primer cuarto del s. II d.C. (Peinado, 2010: 141-142, figs. 4.17-4.18; 2013: 255, fig. 7, 1-2).

Tipo 1b. Se trata de una variante de las jarras Tipo 1a no documentada con anterioridad en Cartuja, aunque la elevada fragmentación de las piezas impide conocer rasgos básicos de su morfología. Con idéntico borde acanalado, se distinguen de las jarras anteriores por presentar un grosor ligeramente inferior y la configuración de un borde trilobulado (Fig. 9, 6). Dos de los ejemplares identificados presentan engobe rojizo al exterior.

Tipo 1c. Clasificadas como «jarras de un asa y cuello ancho» por Serrano (1978: 254, $\mathrm{n}^{\circ} 101$ ), eran conocidas muy parcialmente, aunque los ejemplares recuperados aproximan una jarra piriforme con bordes de $11 / 13 \mathrm{~cm}$ de diámetro ligeramente exvasados y moldurados al exterior, y siempre con un asa puente inmediatamente bajo éste (Fig. 9, 4-5). La concordancia en cuanto a grosor y diámetro permite asociar a estas jarras las abundantes bases de pie diferenciado recuperadas en el testar (Fig. 9, 9), con lo que se trataría de piezas algo menores que las del Tipo 1a, de aproximadamente unos $25 / 28 \mathrm{~cm}$ de altura y unos 18 $\mathrm{cm}$ de diámetro en la panza.

Tipo 1d. La variante corresponde a las jarras de un asa y boca ancha de reducidas dimensiones de la clasificación de Serrano (1978: 252, $\mathrm{n}^{\circ}$ 73-74). Se ha recuperado un ejemplar completo de $5 \mathrm{~cm}$ de apertura del borde y 15,3 cm de altura (Fig. 9, 7), por tanto de dimensiones algo inferiores a las ya conocidas, y con una morfología del borde más emparentada con las Tipo 1c.

Tipo 2. Jarras con dos asas. Todas las variantes documentadas están recogidas en la clasificación de Serrano, aunque se trata de un conjunto cuantitativamente residual y muy fragmentario, por lo que no aporta novedades morfologías.

Tipo 2a. Equivalente a las jarras de dos asas de la clasificación inicial (Serrano, 1978: 252, $\mathrm{n}^{\mathrm{o}} 76$ ), que con sus $12 / 14 \mathrm{~cm}$ de diámetro debían tener unas dimensiones considerables.

Tipo $2 b$. Equivalente a las n ${ }^{\circ}$ 91-92 de la clasificación de Serrano (1978: 252).

Tipo 2c. Equivalente a las de borde vuelto al interior y asas asimétricamente dispuestas sobre el cuello cilíndrico (Serrano, 1978: 253, nº 108-111).

Botella. Distinguidas de las jarras por el cuello netamente diferenciado, más o menos desarrollado en altura y siempre estrecho. Todos los ejemplares documentados en el testar eran ya parcialmente conocidos, correspondientes a la amplia variedad de «jarras de un asa y cuelo estrecho» de la clasificación de Serrano. No obstante, el material recuperado es escaso y muy fragmentario, por lo que no aporta novedades respecto a la mencionada tipología inicial. Aunque responden a parámetros morfológicos muy similares se han distinguido dos tipos en función del borde.

Tipo 1. Con borde vuelto simple (Serrano, 1978: 253-254, $\left.\mathrm{n}^{\circ} 81-82,87\right)$. Uno de los ejemplares adscrito al no 87 de Serrano presenta restos de engobe rojizo.

Tipo 2. Diferenciadas de las anteriores por distintos esquemas de molduración externa del borde, bien con éste ligeramente exvasado (Serrano, 1978: 253254, $\mathrm{n}^{\mathrm{o}} 77,80,83$ ), o entrante (Serrano, 1978: 253$\left.254, n^{\circ} 84\right)$.

Lebrillo. Los lebrillos son, tras las jarras, la producción más abundantemente atestiguada en el testar (17,44\% del total), con un N.m.I. de 234 ejemplares que constituyen el 20,10\% del material común calcáreo. Excepto una de las variantes, las formas identificadas eran ya conocidas con anterioridad. El material se ha agrupado en dos tipos diferenciados por la morfología del borde y la inclinación de las paredes. Ambos tipos están también documentados en el alfar 
del Carmen de la Muralla, en el Albaicín (Fernández, 2004: 204, fig. 8,36 y 38). Como sucede con las jarras comunes del Tipo 1, los principales defectos observados en algunos fragmentos de la serie son deformaciones y estallidos producidos durante la cocción.

Tipo 1. Corresponde a las «vasijas de borde exvasado» de Serrano (1978: 247-248, no41-43), o de «sombrero de copa» (Casado et al., 1999: 135, fig. $4,7)$, caracterizada por un borde en ala y de amplio desarrollo, alzado recto con tendencia a la verticalidad y fondo ápodo. Los ejemplares recuperados en el testar, en total 106 ejemplares, son menos verticales (Fig. 10, 1) y con diámetros comprendidos entre los $27 / 32 \mathrm{~cm}$, aunque en otros sectores de Cartuja alcanzan incluso $40 \mathrm{~cm}$. Un $6 \%$ de los ejemplares presentan el borde completamente horizontal, perfil troncocónico invertido y diámetros que llegan hasta los $39 \mathrm{~cm}$ (Fig. 10, 2). Se trata de un recipiente ampliamente difundido por el Mediterráneo (Serrano, 1978, 248), y por distintas regiones de la Península Ibérica, tanto levantinas y septentrionales (Luezas, 2002: 87-91) como en la Bética, donde su desarrollo se data fundamentalmente en el s. I d.C. (Serrano, 1995: 233; García et al., 2013: 272-273).

Tipo 2. Con 20 individuos, a este tipo corresponden los lebrillos de cuerpo troncocónico invertido de paredes más o menos divergentes (Fig. 10, 3-4), pero siempre con un desarrollo curvado, y con el borde vuelto al exterior en sección triangular o redondeada, si bien en anteriores clasificaciones se ha señalado la relativa variedad de perfiles y dimensiones (Serrano, 1978: 247, $\mathrm{n}^{\circ}$ 39-40; Casado et al., 1999: 135), que en los ejemplares del testar se sitúan entre los $28 / 42 \mathrm{~cm}$.

Tapadera. Se distinguen tres tipos, uno de los cuales no se había documentado con anterioridad.

Tipo 1. Corresponde al conjunto de tapaderas acampanadas clasificadas por Serrano (1978: $243, \mathrm{n}^{\circ}$ 4-6, 9-11) con asidero de remate plano y bordes rectos (Fig. 10,10) o algo vueltos, con diámetros comprendidos entre 10 y aproximadamente $27 \mathrm{~cm}$. Es la tapadera más frecuente en el testar (55 individuos).

Tipo 2. Son las de pequeño tamaño clasificadas por Serrano $\left(1978,243, \mathrm{n}^{\circ} 1-3,8\right)$, hasta $10 \mathrm{~cm}$ de diámetro aproximadamente, generalmente planas y con asidero apuntado. Solo se ha identificado un ejemplar en el testar.

Tipo 3. Se trata de un nuevo tipo caracterizado por la presencia de una pestaña al interior, cerca del borde. Aunque no se han documentado hasta ahora en otros alfares béticos, las tapaderas con pestaña y pasta calcárea están atestiguadas en la producción del área lacial desde comienzos de época imperial hasta el periodo severiano (Olcese, 2003: 99, tav. 33, 3). El tipo está representado en el testar por un solo pequeño fragmento, aunque otro ejemplar recuperado recientemente en el Sector del Colegio Máximo (sobre este sector del alfar: Moreno y Orfila, 2017) permite restituir un diámetro de $25 \mathrm{~cm}$ (Fig. 10, 11).
Orza. Vasijas de forma cerrada y perfil de tendencia globular, de las que se han distinguido tres tipos, de los cuales uno era desconocido con anterioridad.

Tipo 1. La morfología de este tipo corresponde con las orzas y ollas $\mathrm{n}^{\circ} 44-46$ de la clasificación de Serrano (1978, 248-249), si bien la factura en pasta calcárea de los 4 individuos localizados en el testar excluye su exposición al fuego. Entre 11/14,4 cm de diámetro (Fig. 10, 7), presentan borde exvasado y vuelto o engrosado. En estos últimos existen diversas morfologías entre las que destacamos un ejemplar muy fragmentario que puede restituirse a partir de otro ajeno al testar pero procedente del mismo yacimiento (Fig. 10, 8).

Tipo 2. Se trata de una orza desconocida con anterioridad en Cartuja, caracterizada sus mayores dimensiones, en torno a $15,8 \mathrm{~cm}$ de diámetro de apertura, de paredes algo más gruesas que las anteriores, borde engrosado al exterior y por la presencia en el borde de un amplio escalón para asiento de tapadera. La representación del tipo es mínima, con un solo ejemplar identificado, aunque se han localizado otros mejor conservados (Fig. 10,9) en los niveles alterados por la instalación de la acometida hidráulica de los setenta, que afectó de lleno al testar.

Tipo 3. Corresponde a las «orcitas» de la clasificación de Serrano (1978: 251, $\mathrm{n}^{\circ} 70$ ), caracterizadas por sus reducidas dimensiones, entre $8 / 10,5 \mathrm{~cm}$ de diámetro de apertura, borde vuelto, y paredes en ocasiones de escaso grosor. Con 34 individuos identificados, es el tipo más frecuente de orza del testar, algunos de los cuales presentan pequeñas molduras en el borde de ejecución muy cuidada (perfiles muy similares se produjeron en modelos engobados, fig. 12, 11-12). Al menos tres individuos adscritos al tipo presentan leves deformaciones producidas durante su cocción.

Fuente. La serie está representada por un único tipo (Tipo 1), perteneciente a los «grandes cuencos con forma de lazo» de la clasificación de Serrano (1978: 246, $\mathrm{n}^{\mathrm{O}} 30$ ), más tarde definidos como fuentes (Casado et al., 1999, 135). Los ejemplares recuperados, entre 28/32 cm de diámetro de apertura (Fig. 10, 5-6), no presentan en general novedades respecto a los rasgos ya conocidos, con la característica acanaladura profunda en el labio y las asas sobrepasando la línea de borde. Un ejemplar presenta unas paredes acusadamente oblicuas (Fig. 10, 5), al modo de algunas piezas producidas en Los Castillones, Málaga, fechadas entre la segunda mitad del s. I y comienzos del II d.C. (Serrano, 1995: 233, fig. 5, 35). A una cronología similar para los ejemplares de Cartuja apunta el estudio evolutivo realizado a partir de las producciones de Andalucía Occidental (García et al., 2013: 269-270).

Plato. Escasamente representados en el testar, se registran dos tipos, ambos ya clasificados con anterioridad.

Tipo 1. Corresponde a los denominados «platitos» (Serrano, 1978: 250, no 62-65), o «platos con 
baquetón» (Fernández, 2004: 209), de los que distinguimos dos variantes en función de sus dimensiones.

Tipo 1a. De reducidas dimensiones, más próximos al concepto moderno de escudillas, entre 9 y $13 \mathrm{~cm}$ de diámetro (Fig. 10, 13). Uno de los ejemplares presenta restos de engobe castaño.

Tipo 1b. De mayor capacidad, con diámetros superiores a $13 \mathrm{~cm}$, aunque en el testar no superan los $18,4 \mathrm{~cm}$. Dos individuos presentan una morfología del borde más exvasado que los ejemplares hasta ahora conocidos (Fig. 10, 14).

Tipo 2. Corresponde a $\operatorname{los}$ platos $n^{\circ} 28-29$ y 31 34 de la clasificación de Serrano, concretamente a los el Grupo 1, de labio redondeado, cuerpo de paredes divergentes generalmente abombadas y amplio fondo plano (Serrano, 1978: 246). Está representado en el tramo excavado del testar por un solo fragmento.

Vaso. Serie representada en el vertido por un solo tipo (Tipo 1) perteneciente a los «vasos de cuerpo ovoide» de la clasificación de Serrano (1978: 250, nº 66-67). $\mathrm{Su}$ representación es mínima, con un solo ejemplar identificado.

Cuenco. Serie representada por un solo tipo (Tipo 1), que agrupa los «platos hondos» de la clasificación de Serrano $\left(1978,249, \mathrm{n}^{\circ}\right.$ 53-55, 57-58), también denominados «cuencos hemisféricos» (Fernández, 2004: 209). De los 33 individuos identificados, tan solo uno presenta una pequeña hendidura en la parte interna del labio (Fig. 10, 12), presentando el resto la característica inflexión del borde hacia el interior o vertical. Al menos dos individuos presentan deformaciones del borde producidas durante su cocción.

\subsection{CERÁMICA DE COCINA}

La cerámica de cocina constituye el 25,96\% del conjunto del vertido excavado. Como se ha señalado anteriormente, toda la producción está realizada con pastas muy similares y mediante cocción oxidante. Se han identificado 5 series y hasta 8 distintos tipos cerámicos, cuantificados por N.m.T en la figura 8. En líneas generales se han identificado menos piezas defectuosas que en el caso de las comunes calcáreas, aunque se detectan algunos fragmentos con malformaciones similares, fundamentalmente deformaciones y estallidos, de nuevo producidos en el proceso de cocción.

Olla. Las ollas es la producción de cocina más abundante en el vertido, constituyendo el $44 \%$ de esta clase cerámica. El material de esta serie se ha agrupado en dos tipos básicos, uno de los cuales presenta novedades respecto a las ollas anteriormente conocidas.

Tipo 1. Corresponde a las ollas de perfil globular, base estrecha y plana, y borde vuelto ya recogidas en la clasificación inicial de la vajilla de Cartuja (Serrano, 1978: 248-249, no 44-46). En ninguno de los 147 individuos identificados hay indicios de asas, y la mayor variedad se encuentra en las dimensiones, que van desde los 10 a los $16 \mathrm{~cm}$ diámetro de apertura, y en los bordes, en ocasiones provistos de pequeñas molduras externas, y que pueden tener el labio redondeado, apuntado, plano, o ligeramente biselado (Fig. 11, 8-10). Al menos ocho fragmentos de ollas de este tipo presentan deformaciones.

Tipo 2. Se trata de un tipo no identificado con anterioridad que con sus 7 individuos inventariados es claramente minoritario respecto a las ollas del Tipo 1. Se caracteriza por el borde poco desarrollado y engrosado al exterior, que llega en algunos casos a disponerse a modo de cinta, y por la presencia de una inflexión más o menos desarrollada a escasos centímetros del borde que le confiere un perfil abolsado (Fig. 11, 1113). Ninguna ha conservado la base. Presenta unas dimensiones que no sobrepasan los 13,6 cm de diámetro, aunque las más frecuentes se sitúan en torno a $11 \mathrm{~cm}$.

Plato. Los platos constituyen un 38,9\% del material de cocina documentado, por lo que es, tras las ollas, la segunda serie cuantitativamente más importante. El material se agrupa en dos tipos ya conocidos en el repertorio de Cartuja.

Tipo 1. Corresponde a los platos de pared curvada, fondo plano, y con una acanaladura en el borde que configura un labio bífido (Serrano, 1978: 247, n 36-37). Los 63 ejemplares identificados se sitúan entre los 23/25,2 $\mathrm{cm}$ de diámetro de apertura, y hasta $8 \mathrm{~cm}$ de altura. La base presenta generalmente una tendencia a la concavidad, y la acanaladura del labio está en la mayoría de los casos muy poco desarrollada (Fig. 11, 1). El tipo repite fielmente un modelo, también con labio bífido, producido en el área lacial en época tardorepublicana y a lo largo del s. I d.C. (Olcese, 2003: 86, tav. 15, 1). Un número reducido de piezas presenta algunas deformaciones, sobre todo en las partes más delgadas de las bases.

Tipo 2. Se diferencian de los anteriores por la ausencia de acanaladura en el labio, siendo este generalmente redondeado, bien inclinado hacia el interior o recto, (Serrano, 1978: 246, $\mathrm{n}^{\circ}$ 28-29, 32-34). Los 73 individuos identificados presentan un diámetro entre $18 / 19,8 \mathrm{~cm}$, por tanto de dimensiones más reducidas, y tienen también una base de tendencia cóncava (Fig. $11,2)$. En tres ejemplares se aprecian pequeñas deformaciones, y uno de ellos aparece partido en dos mitades a causa de su estallido en el horno, pues la fractura está rubefactada y deformada.

Cazuela. Las cazuelas constituyen la tercera serie más numerosa, alcanzando el $15,7 \%$ de las producciones de cocina. Los 55 individuos se agrupan en dos tipos que eran ya parcialmente conocidos, si bien la buena conservación de los ejemplares de unos de ellos (Tipo 1), el más numeroso, ha permitido conocer su morfología y principales variantes.

Tipo 1. Corresponde a los denominados «cuencos carenados» de la clasificación de Serrano (1978: 
245-246, n²4), más tarde clasificados dentro de la serie cazuelas (Casado et al., 1999: 136, fig. 5, 3). Se trata de cazuelas de paredes más bien gruesas provistas de una destacada carena en la parte superior del cuerpo y una base estrecha y plana, con tendencia a la concavidad. Con 53 individuos identificados es la cazuela más frecuente del testar, de la que pueden distinguirse algunas variantes menores. La variante más abundante presenta labio plano y un borde ligeramente engrosado generalmente indicado al exterior (Fig. 11, 3 y 6), frecuentemente con una incisión externa decorativa ubicada entre el borde y la carena (Fig. 11, 5). Esta variante presenta un diámetro máximo entre $20 / 24 \mathrm{~cm}$. Una variante de éstas presenta el labio biselado y las paredes de la parte superior del cuerpo algo combadas (Fig. 11, 4). Por último, se documentan dos individuos de mayor tamaño, entre $30 / 31 \mathrm{~cm}$ de diámetro, que presenta el borde engrosado al exterior en sección triangular (Fig. 11, 7). Cazuelas carenadas similares están atestiguadas en niveles de época neroniana-flavia en Roma (Quercia, 2008: 203, fig. 3, 12), y en el Levante Peninsular en contextos de finales del s. I d.C. (Escrivá, 1995: 176, fig. 7, 6). En la Bética se produjeron cazuelas de este tipo en talleres altoimperiales malagueños como los del Castillón y Teba (Serrano, 1997: 220, figs. 10-11).

Tipo 2. Con solo dos individuos inventariados, el tipo corresponde a los denominados «cuencos sin estrías» de la clasificación de Serrano (1978: 245, nº 20), posteriormente definido como cazuela (Casado et al., 1999: 136).

Tapadera. Se registra un único individuo muy fragmentario, en principio con un diámetro similar a las tapaderas calcáreas del Tipo 1. Tapaderas de cocina similares se han registrado en la Vega de Granada en niveles del s. II d.C. (Ruiz et al., 2010, figs. 10, 5 y 12, 8), quizás procedentes de Cartuja.

Jarra. De la serie jarra se registran solo 4 individuos, todos ellos con la boca trilobulada (Tipo 1), aunque debido a su elevada fragmentación se desconocen sus características morfológicas y posibles variantes. Aunque eran desconocidos en Cartuja, jarras trilobuladas en pastas de cocina se produjeron en el complejo altoimperial de Andújar durante todo el periodo de actividad del alfar (Peinado, 2010: 150, figs. 4.40-4.43; 2013b: 274-275, figs. 5-6).

\subsection{CERÁMiCA ENGOBADA}

La cerámica engobada constituye el 15,17\% del conjunto del vertido excavado. Pese a su minoritaria representación frente a la vajilla común calcárea y de cocina, el material aporta importantes novedades respecto a este género de producciones, identificándose 3 nuevos tipos y permitiendo avanzar en la restitución de otros conocidos solo parcialmente. En total se han registrado 6 series y 10 tipos cerámicos, cuya cuantificación queda reflejada en la figura 8 . Además de puntuales fragmentos con claros signos de deformación, el defecto más frecuente de esta clase cerámica en el vertido son los engobes pasados de cocción, que dan lugar a superficies total o parcialmente ennegrecidas, e incluso corroídas. Este tipo de defecto ha afectado al análisis de la coloración y características de los engobes en una buena parte del conjunto recuperado.

Jarra. La presencia de la serie jarra es absolutamente dominante en el conjunto de material engobado, con un $71,4 \%$ del total recuperado, constituyendo el $11,40 \%$ de la cerámica desechada en el tramo del testar excavado. Esta alta cuantificación se debe a uno de los dos tipos identificados (Tipo 1).

Tipo 1. Corresponde a las denominadas «jarritas bitroncocónicas», definida como una pequeña jarra de un asa y pie lleno individualizado, cuyo perfil presenta un destacado ángulo hacia la mitad del alzado (Serrano, 1975: 220-222, fig. 2,2; Fernández, 2004: 210, fig. $12,56)$. Se trata de piezas de cuidada ejecución, muy características del alfar de Cartuja, con un marcado carácter local, y que con 143 individuos inventariados asumen el grueso de las producciones engobadas recuperadas en el vertido. El material recuperado confirma la estandarización de estas producciones, documentándose dos variantes. El 90\% corresponde al modelo pequeño, con un diámetro de apertura entre 9,2/9,6 cm y una altura de unos $10 / 12 \mathrm{~cm}$, generalmente con dos acusadas estrías ornamentales por encima del pie (Fig. $12,1)$. Los casos no afectados por sobrecocción presentan mayoritariamente un homogéneo engobe rojizo o anaranjado que suele gotear al interior del borde, aunque un $4 \%$ de las piezas no están engobadas. El 6\% de los individuos corresponde a la variante algo más grande, con diámetros de apertura entre $11 / 12 \mathrm{~cm} \mathrm{y}$ $13 / 14 \mathrm{~cm}$ de altura, provista de un friso burilado bajo la carena a partir del cual se desarrollan hasta el pie una serie de líneas incisas ornamentales (Fig. 12, 2).

Tipo 2. Con tan solo 2 individuos identificados, se trata de una producción no atestiguada con anterioridad, definida como una pequeña jarra de un asa y pico vertedor, de 6,9 cm de apertura (Fig. 12, 3). Ninguno de los ejemplares conserva la base, aunque las dimensiones y la morfología globular de la parte baja parecen coincidir con algunas bases planas engobadas recuperadas en el testar. En los dos ejemplares identificados el engobe externo conservado es rojizo. El tipo parece una imitación de la forma 21 de TSH, documentada en la producción tardía de Andújar (Fernández, 2015: 264-265, fig. 44)

Botella. Con 3 tipos identificados, 2 de ellos nuevos, las botellas constituyen el 10,9\% del material engobado.

Tipo 1. Inicialmente denominadas «jarritas de un asa» (Serrano, 1975: 226, fig. 4, 4), eran conocidas muy parcialmente, por lo que el relativamente buen 
estado de conservación de los 20 individuos recogidos ha permitido definir las principales características de estos recipientes. Se trata de una botella de base ancha y plana, cuerpo de perfil globular con hombro marcado, cuello cilíndrico poco desarrollado del que arranca un asa puente que muere en el hombro de la pieza. Borde en alero con pestaña superior. Suelen presentar decoración incisa en el hombro. En los casos bien conservados, el engobe es generalmente rojizo no uniforme, con algunas bandas grisáceas con frecuencia coincidentes con las líneas incisas, aunque el 20\% de los ejemplares no ha conservado resto alguno. El modelo se produce con dos tamaños, el más grande con un diámetro de apertura de $6,2 \mathrm{~cm}$ y unos $28 \mathrm{~cm}$ de altura (Fig. 12, 4-5), y otro algo más reducido de $5,3 \mathrm{~cm}$ de diámetro y aproximadamente unos $24 \mathrm{~cm}$ de altura (Fig. 12, 6-7). El tipo guarda cierta relación formal con algunas piezas béticas, por ejemplo con algunos ejemplares malagueños también engobados (Serrano, 1997: 222, fig. 25), pero las particularidades del granadino lo convierten, como sucede con las jarras engobadas del Tipo 1, en un producto de fuerte carácter local.

Tipo 2. Se trata de una botella no atestiguada con anterioridad de la que se contabiliza un único individuo. Se trata de una botella cuadrangular de esquinas redondeadas, fondo ápodo, cuerpo de paredes ligeramente divergentes y hombro marcado (Fig. 12, 8). El cuello es cilíndrico y presenta una única asa que arranca de la parte inferior del cuello para morir en el hombro. Desconocemos la morfología del borde puesto que el ejemplar no lo conserva. Debía tener unos $18 / 20 \mathrm{~cm}$ de altura, con una base en de $9,5 \mathrm{~cm}$ y $2,4 \mathrm{~cm}$ de diámetro en el cuello. El perfil recuerda a la forma 55 de TSH, aunque en cualquier caso parece tratarse de un diseño local para el que no hemos localizado paralelos. La base de la pieza estalló fracturándose durante la cocción, tal y como indican la superficie de fractura. El interior se encuentra rubefactado, pero el exterior conserva en relativo buen estado un engobe anaranjado y uniforme.

Tipo 3. Al tipo se adscribe un solo ejemplar muy fragmentario que conserva solo un tramo del cuerpo y del cuello con engobe rojizo (Fig. 12, 10), aunque en otras unidades del yacimiento se localizan otros fragmentos que parecen corresponder a este mismo tipo de pequeña botella engobada de cuello alto y estrecho. Entre estos otros fragmentos destaca un borde (de UEN 53.066), algo exvasado y de labio ligeramente engrosado, que conserva en la parte superior del cuello el arranque de una sola asa (Fig. 12, 9). De aceptarse la pertenencia de este modelo de bordes al Tipo 3, se trataría de una clase de botellas que se desarrollan en Italia desde el periodo tardorepublicano hasta la etapa flavia (Olcese, 2003: 96, tav. 30, 1), y que serían recepcionadas en la Bética hacia mediados del s. I d.C., según parecen indicar algunos ejemplares fragmentarios de Andújar (Peinado, 2010: 144; 2013: 257, fig. 9, 6-8).

Orza. Los dos tipos identificados son de muy reducidas dimensiones, $\mathrm{y}$, aunque en la clasificación tradicional aparecen citadas como orzas, urnas, o incluso botella, presentan cierta problemática en su definición funcional, pudiendo ser destinadas a otros usos domésticos, tales como pequeños recipientes de mesa. La serie constituye el 11,8\% del material engobado exhumado en el vertido.

Tipo 1. Corresponde a las denominadas «pequeñas orzas» y «pequeñas urnas» de la clasificación de Serrano (1975: 222, figs. 2, 5 y 3, 1 respectivamente), con perfil globular, borde exvasado y fondo ápodo o individualizado. Los 22 individuos del vertido no conservan la base en ningún caso, tienen, en los casos bien conservados, engobes anaranjados o rojizos uniformes, y, pese a sus reducidas dimensiones, presentan los bordes moldurados según distintos esquemas (Fig. 12, 11-12). Como señaló Serrano, estas mismas formas se producen en vajilla común (nuestra orza Tipo 3), aunque con la característica pasta calcárea y paredes de mayor grosor, que en estas engobadas se sitúan entre $0,2 / 0,3 \mathrm{~cm}$.

Tipo 2. Corresponde a unos pequeños recipientes globulares con cuello cilíndrico y con decoración burilada inicialmente clasificados como «botellas» (Serrano, 1975: 224, fig. 3, 2). Sus reducidas dimensiones plantean, sin embargo, que se emplearan como pequeños contenedores, o incluso como vasos, dada su proximidad formal a modelos de paredes finas como Mayet XXI, situación que concuerda con el finísimo grosor de 0,2 cm de los ejemplares cartujanos. Tan solo se contabilizan 2 individuos bastante fragmentarios en el vertido, con engobe rojizo y sin decoración burilada.

Cazo. Con 4 individuos muy fragmentarios identificados, corresponde a un único tipo (Tipo 1), los conocidos «cazos hondos de asa plana» (Serrano, 1975: 220, fig. 2, 1) producidos localmente también en TSH (Serrano, 1979: 64, fig. 15, 111). Las características de los ejemplares del vertido son, en lo conservado, idénticas a las señaladas por Serrano.

Plato. Los 5 individuos identificados corresponden a las imitaciones engobadas de la forma 15/17 de TSH (Serrano, 1975: 224, fig. 4, 2). Los individuos recuperados responden a las mismas características ya indicadas por la mencionada autora. La forma 15/17 de TSH está, como se ha señalado, presente también en el vertido, y constituye una de las formas de sigillata más desarrolladas en Cartuja (Serrano, 1979: 34-36, fig. 2), atestiguándose igualmente en el alfar del Carmen de la Muralla (Fernández, 1997; 2004: 200, fig. 3, 1).

Taza. Con solo 3 individuos contabilizados, corresponde a los «recipientes de una o dos asas» de la clasificación de Serrano (1975: 224, fig. 3, 4). Sus dimensiones y morfología parecen identificarlo con una taza, aunque la elevada fragmentación de los ejemplares, tanto de los estudiados por Serrano como los del presente vertido, impide avanzar en su restitución. 

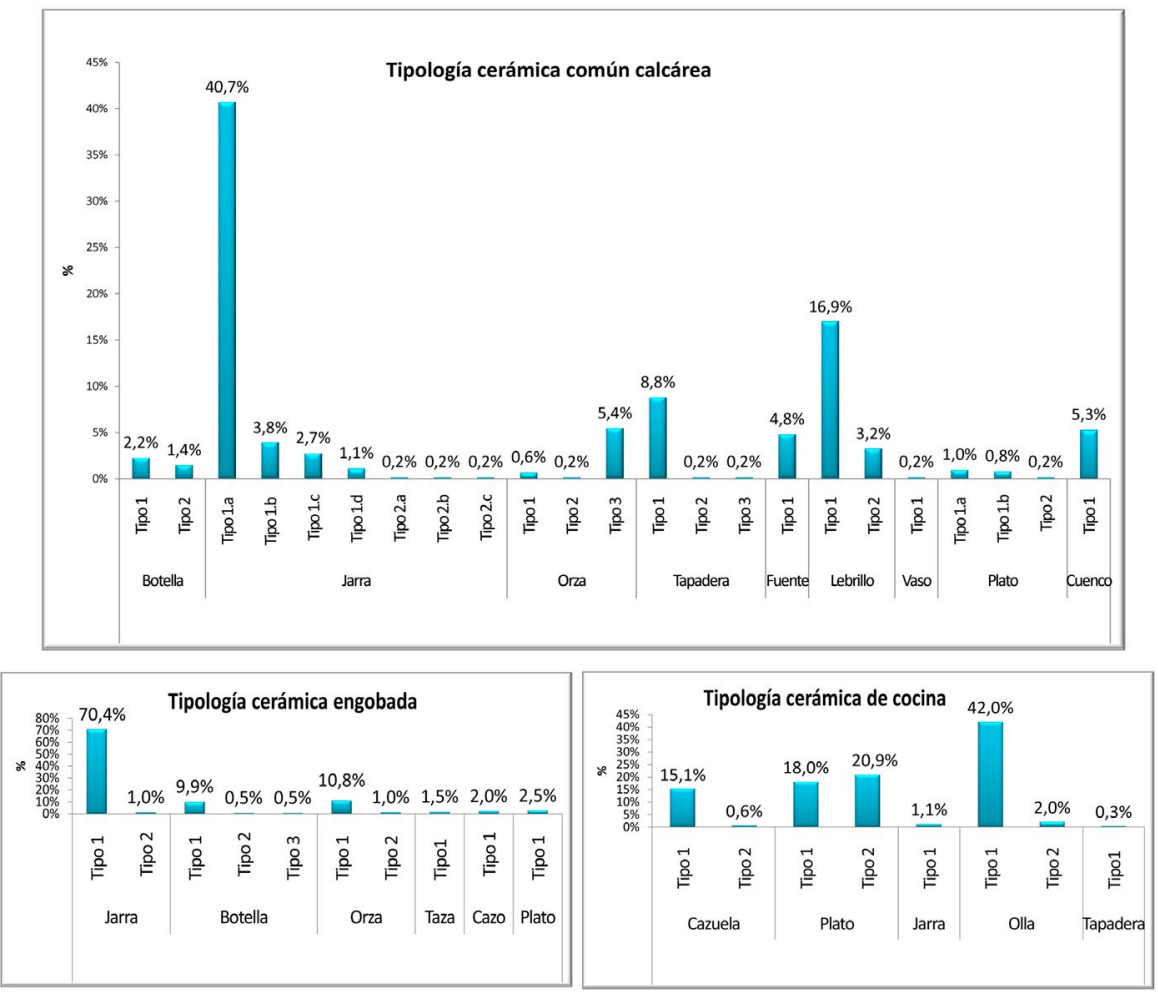

Figura 8: Porcentaje a partir del N.m.T. de los tipos documentados en el testar.

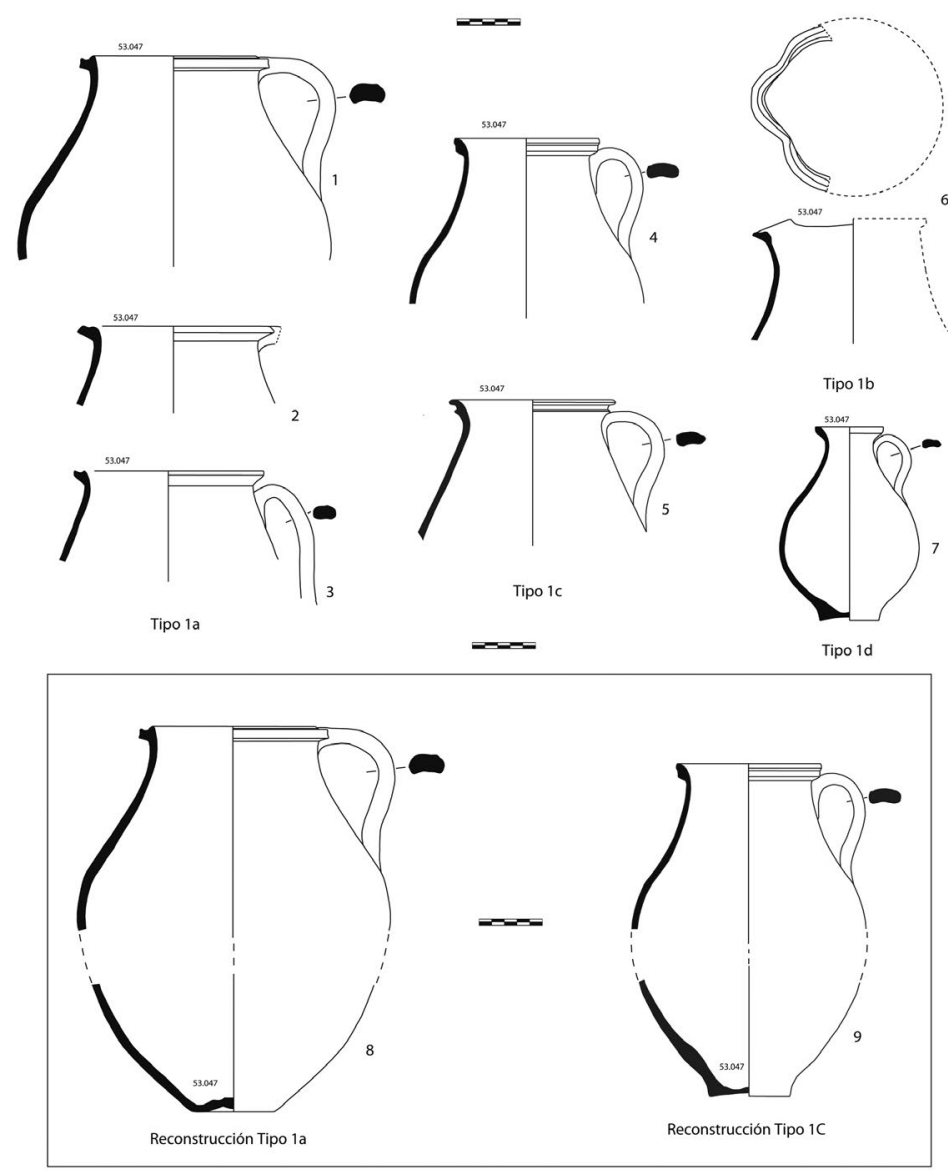

Figura 9: Jarras Tipo 1 de la clase común calcárea. 


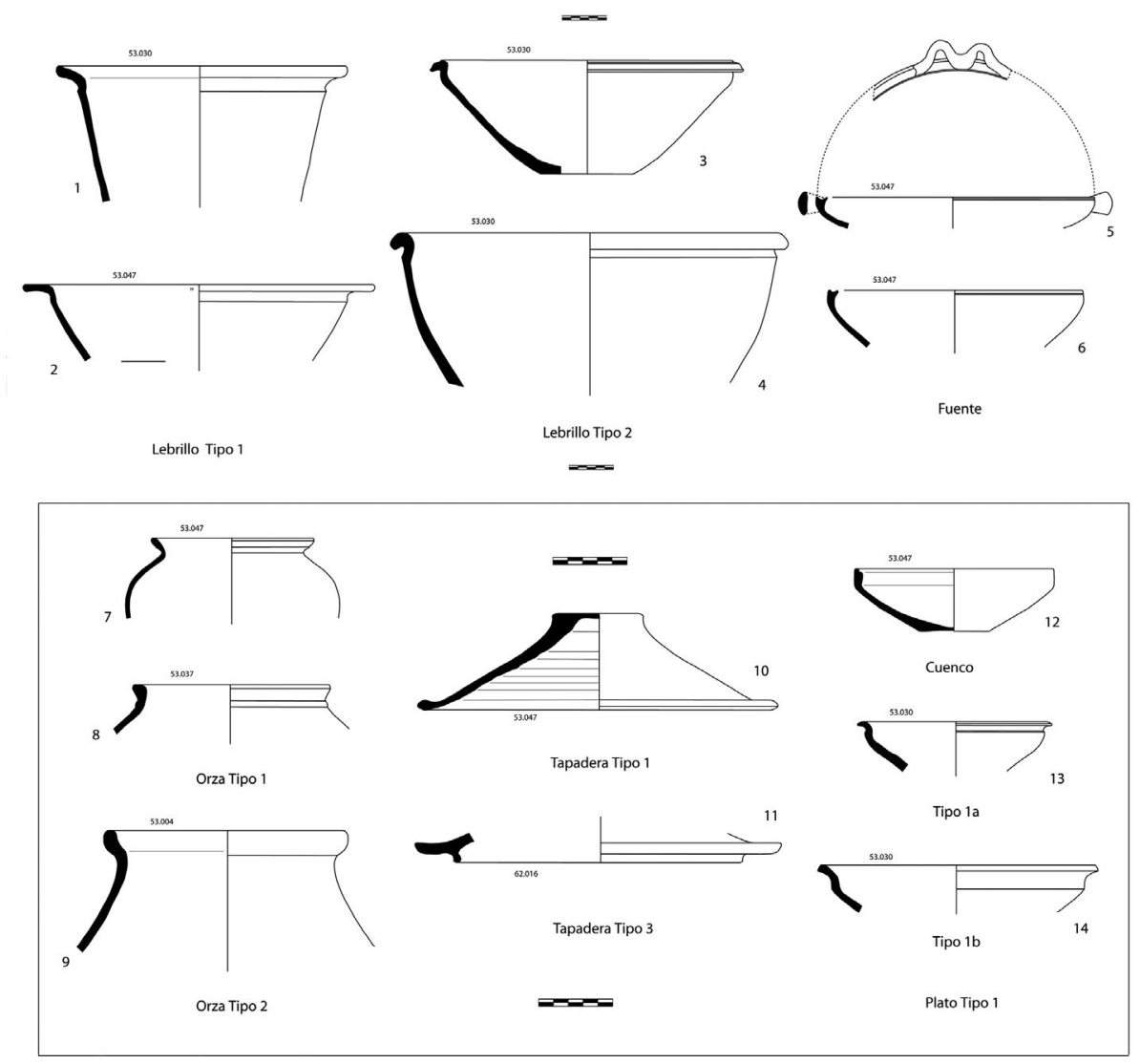

Figura 10: Varios común calcárea.
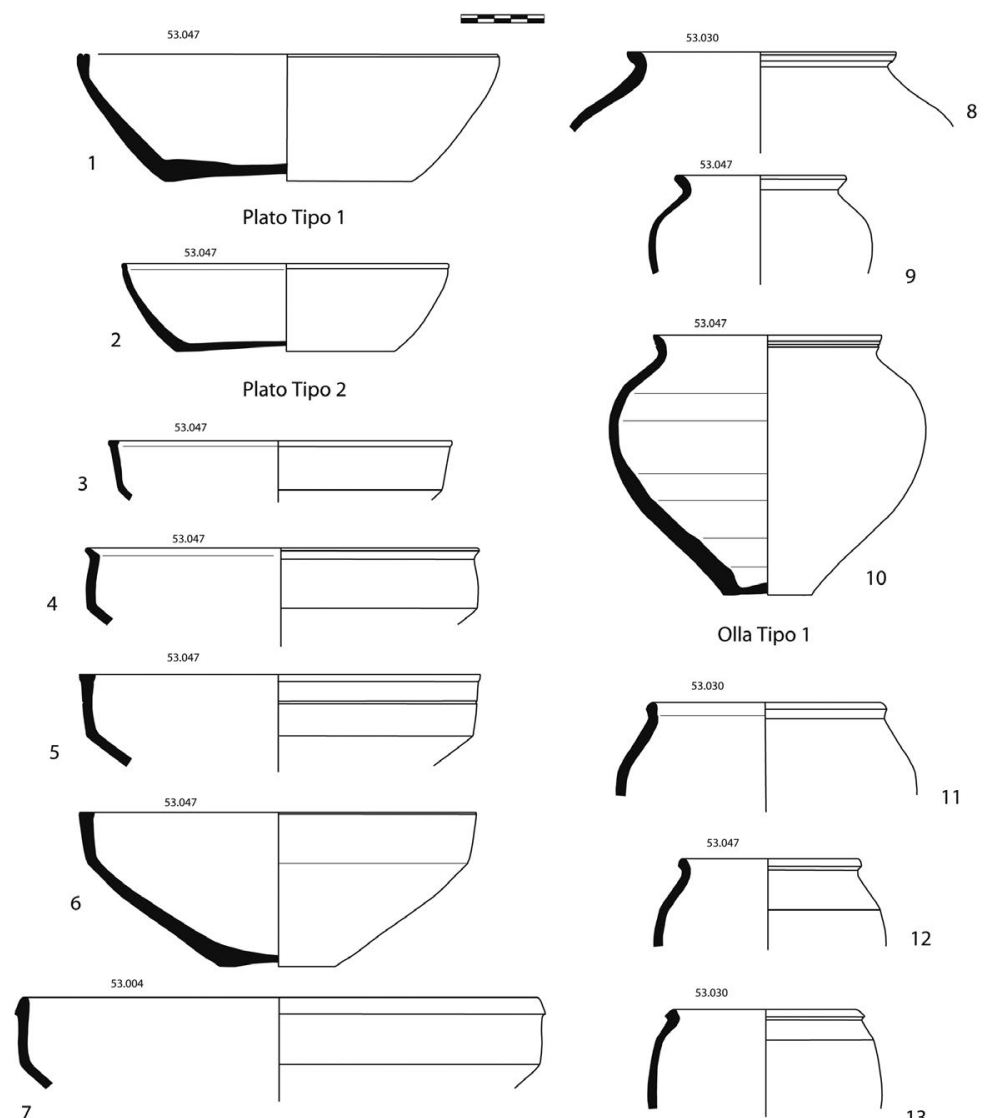

Cazuela Tipo 1

$=$

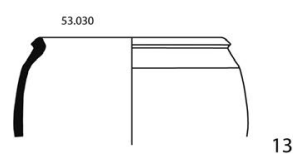

Olla Tipo 2

Figura 11: Varios cocina. 


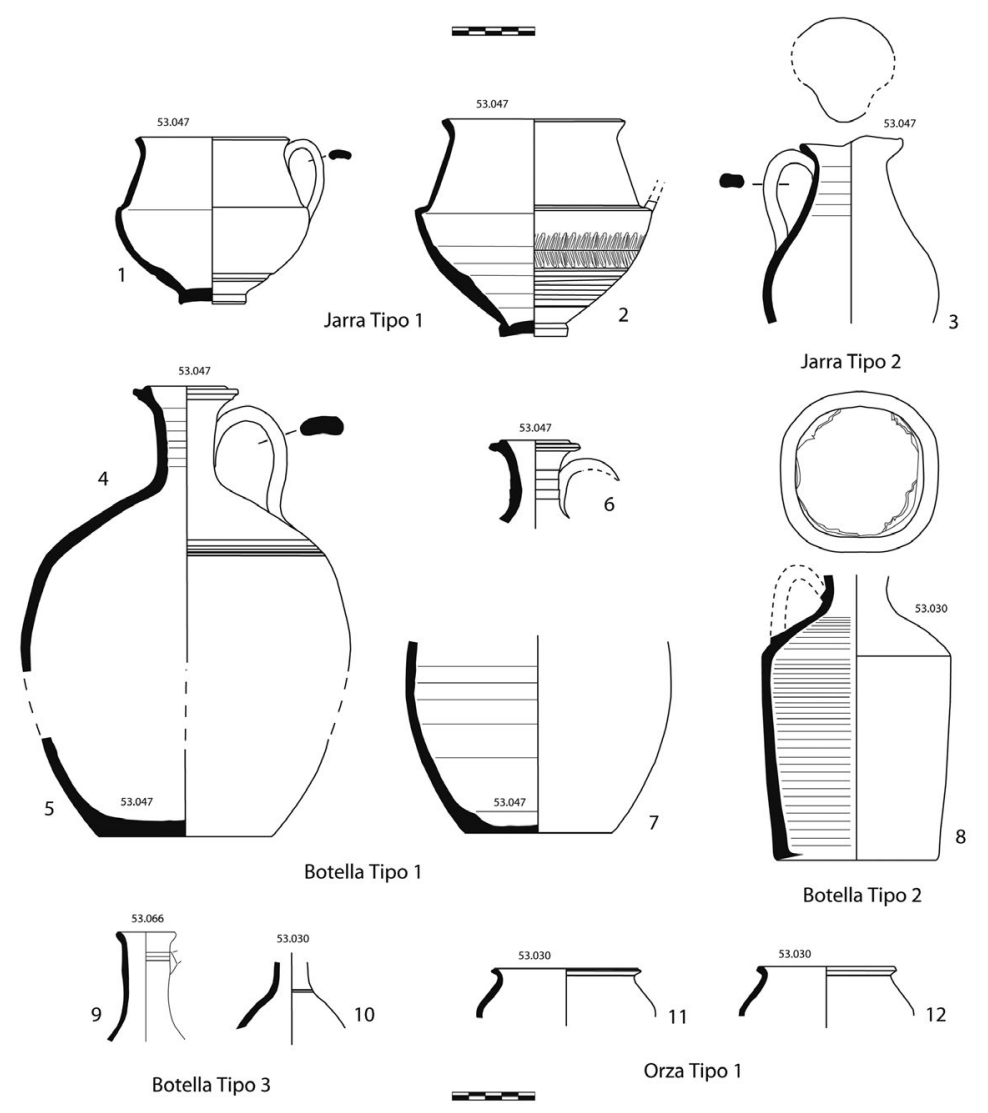

Figura 12: Varios engobada.

\section{DISCUSIÓN}

Para aproximar una datación del vertido analizado debe tenerse en cuenta, además de su caracterización artefactual, el encuadre cronológico del horno y del resto de sus niveles de abandono. Dado que no se han excavado niveles fundacionales asociados al Horno D4, su datación debe efectuarse de modo orientativo mediante las características de su sistema constructivo, definido por el empleo exclusivo de material latericio y rellenos de arcillas. Este sistema es equivalente al del conjunto de hornos del Sector del Beiro contextualizados en la tercera de las fases estratigráficas establecida por M. Sotomayor (1970; 1991; Casado et al., 1999: 131), entre los cuales destacan por su paralelismo tipológico con el D4 los Hornos 1 y 3. Esta tercera fase, datada entre la segunda mitad del s. I e inicios del s. II d.C., constituye el momento de mayor actividad del alfar, y a ella se adscriben las más importantes cotas de producción de TSH y la aparición de la mayor parte de los tipos conocidos de vajilla engobada local. Por ello, tanto el sistema constructivo del Horno D4 como el registro artefactual del vertido y del resto de niveles de abandono se encuadran en esta época de apogeo de la producción. Más complejo resulta concretar esta datación dentro del periodo aludido, aunque la presencia de las cazuelas carenadas del Tipo 1, que aparecen en el área lacial en el periodo neroniano-flavio, o el perfil de las fuentes de asas en forma de lazo (Tipo 1), que corresponde a un momento ya avanzado, son indicios que plantean una cronología entre la etapa flavia y comienzos del s. II d.C. para el vertido. A ello apuntan también las jarras calcáreas del Tipo 1a, depositadas masivamente en el testar, cuyos contextos de uso se fechan en el Alto Guadalquivir principalmente en época flavia, cesando su producción en Andújar hacia el primer cuarto del s. II (Peinado, 2013a: 255, 258).

El desconocimiento del grado de representatividad del repertorio recuperado respecto al conjunto del vertido constituye un problema crucial que impide interpretar con certeza los datos obtenidos en relación a la producción de este Sector de Teología. No obstante, como se ha señalado en el apartado 3, el repertorio cerámico documentado en el vertido no se ve sustancialmente alterado en el resto de niveles de abandono del yacimiento donde se emplazan los hornos D3 y D4, o de los distintos estratos excavados bajo la actual calle Prof. Vicente Callao. Esta relativa homogeneidad del repertorio conocido implica que la actividad del sector corresponde a la misma fase productiva, y posiblemente no debió extenderse demasiado en el tiempo. Pero también permite, con la debida cautela, caracterizar de modo preliminar la producción de este sector, matizando algunas de las diferencias respecto al vecino sector del Beiro.

La residualidad de TSH en el vertido se refleja en todos los niveles del yacimiento, y también en el resto de estratos excavados en el sector, por lo que en 
principio parece que éste quedó desvinculado de la producción de este tipo de vajilla, contrastando con los datos del Sector del Beiro9 ${ }^{9}$, donde su fabricación está evidenciada por su cuantificación, presencia de moldes, y la identificación de un horno rectangular de galería única destinado a su cocción (Horno 2, Sotomayor, 1970; Casado et al., 1999: 129-130; Fernández, 2004: 207).

Es muy probable que en el sector se produjera material de construcción cerámico, lo cual se apoya fundamentalmente en la identificación de un pequeño vertido de grandes fragmentos de tegulae también sobre el Horno D4, y en la propia tipología cuadrangular y de doble galería de los Hornos D1 y D4, la cual se ha vinculado con este tipo de producción (Bermúdez, 1982-83: 223-225). En esta misma línea apuntan las observaciones de M. Sotomayor, quien advirtió la presencia de este tipo de muestras en torno al Horno D1, relacionando igualmente los Hornos 1 y 3 del Sector del Beiro, de idéntica tipología, con la cocción de estos materiales (Sotomayor, 1970: 715).

Con los datos actualmente disponibles, tanto del testar como de la totalidad de los contextos de la zona excavados, la producción de cerámicas comunes debió ser la actividad principal del Sector de Teología. En líneas generales, y salvo excepciones como los morteros, embudos o cantimploras, que no han sido identificados en el sector, el repertorio es equiparable al del vecino Sector del Beiro por lo que se refiere a clases y series cerámicas. Sin embargo las diferencias son acusadas respecto a los tipos cerámicos, que en Teología son muy limitados en comparación con la gran variedad atestiguada a orillas del Beiro. Esto podría en principio asociarse a la mayor envergadura de este último sector, tal como indica también la alta concentración de estructuras productivas documentada, pero también a una actividad más prolongada en el tiempo, y por tanto con una producción más variada.

La clase cerámica mejor representada en Teología es la común calcárea, y pese a la importante limitación de tipos registrados, éstos presentan una incidencia cuantitativa en la producción equiparable con sus homólogos del Beiro. En este sentido, las jarras del Tipo 1a, los lebrillos Tipo 1, y las tapaderas Tipo 1, productos masivamente representados en el testar, son también de los más abundantes en el Sector del Beiro, aunque destaca notablemente en Teología la presencia de las jarras, de las que se amortizaron posiblemente distintas hornadas en el Horno D4, pues se han contabilizado 255 individuos frente a los 71 fragmentos de bordes contabilizados en las campañas de Sotomayor en el Sector del Beiro ${ }^{10}$. Además de permitir el análisis de las distintas variantes de jarras, en el testar se han identificado tipos calcáreos hasta ahora desconocidos, como las orzas Tipo 2, o las tapaderas con pestaña Tipo 3, en ambos casos en proporciones muy residuales, aunque igualmente constatadas en el entorno del Colegio Máximo.

Ollas y platos son también las producciones de cocina más frecuentes en las instalaciones junto al río, destacando fundamentalmente en Teología la identificación del nuevo tipo de olla de cuerpo abolsado (Tipo 2), y de las distintas variantes de las cazuelas carenadas del Tipo 1, que llegan a adquirir, tras ollas y platos, una cuantificación destacada en el testar.

En cuanto a las cerámicas engobadas, se observa la ausencia de algunas formas producidas junto al Beiro, como serían algunos modelos de copas y tazas, al tiempo que otras son residuales, como sucede con los abundantes cazos de asa plana, y platos, estos últimos pertenecientes solo a una de las variantes recogidas por Serrano. Por el contrario se han identificado dos nuevos tipos de botellas (Tipos 2 y 3 ) y una nueva jarra de pico vertedor derivada de la forma 21 de TSH (Tipo 2), aunque en los tres casos en proporciones residuales. Cierta coincidencia se da en el caso de las jarras bitroncocónicas del Tipo 1, que es el producto engobado mejor representado en todo el Sector de Teología, y que alcanza una presencia destacada también en la zona productiva del Beiro ${ }^{11}$. Estos datos señalan la relevancia de este tipo de pequeña jarra de mesa en ambos sectores productivos, contrastando con el sector emplazado en el entorno del Colegio Máximo, donde son residuales, como el resto de vajillas engobadas. Se trataría, pues, de una de las producciones engobadas más características del alfar, cuya difusión abarcaría al menos el área periurbana de Iliberri (véase, por ejemplo: Rodríguez et al., 2014: fig. 5), y los establecimientos de la Cuenca Alta del Genil (Román y Fernández, 2012: 165, Ilus. 59).

En definitiva, las instalaciones productivas del Sector de Teología se originarían en plena época de apogeo de la producción del alfar posiblemente para intensificar fundamentalmente la producción de las distintas clases de cerámicas comunes, aunque probablemente también para reforzar las partidas de material de construcción cerámico. No obstante, estas conclusiones deben considerarse preliminares en espera de futuras intervenciones e investigaciones de mayor calado en este espacio.
9. La producción de TSH está igualmente atestiguada por su alta cuantificación y presencia de moldes en un sector productivo del alfar recientemente identificado en las inmediaciones del Colegio Máximo de Cartuja, a unos $450 \mathrm{~m}$ de distancia del Beiro (Moreno y Orfila, 2017).
10. De ellos, 11 fragmentos eran de color «ladrillo» (Serrano, 1978: 252), posiblemente producidos con pastas de cocina.

11. Se identificaron 12 completas, 196 bordes, 37 asas, 233 fragmentos de pared, y 70 fondos (Serrano, 1975: 222). 


\section{REFERENCIAS}

Balfet, H., Fauvet-Berthelot, M.F. y Monzon, S. (1983). Pour la normalisatión de la description des poteries. París: Centre National de la Recherche Scientifique.

Bermúdez Medel, A. (1982-83). Interés, problemática y metodología del estudio del material de construcción de tipo cerámico en la arquitectura romana de Tarraco. Bulletí Arqueológic, 4-5, 197-234.

Casado, P. J., Burgos, A., Orfila, M., Alcaraz, F., Cassinello, S., Cevidanes, S. y Ruiz, S. (1999). Intervención arqueológica de urgencia en el Alfar Romano de Cartuja (Granada). Anuario Arqueológico de Andalucía 1994, 3, 129-139.

Coll, J. (2008). Hornos romanos en España. Aspectos de morfología y tecnología. En D. Bernal y A. Ribera (Eds.). Cerámicas hispanorromanas. Un estado de la cuestión (pp. 113-125). Cádiz: Universidad de Cádiz.

Compaña, J. M., León-Reina, L. y Aranda, M. A. G. (2010). Archaeometric characterization of Terra Sigillata Hispanica from Granada Workshops. Boletín de la Sociedad Española de Cerámica y Vidrio, 49(2), 113-119.

Cortese, C. (2005). La ceramiche comuni: problema generali e crieri di classificazioni. En D. Gandolfi (Ed.). $L a$ cerámica e $i$ materiali di eta romana. Classi, produzioni, commerci e consumi (pp. 325-338). Bordiguera: Istituto Internazionale di Studi Liguri.

Cuomo di Caprio, N. (2007). Ceramica in Arqueologia 2: Antiche tecniche di lavorazione e moderni metodi di invagine. Roma: L'Erma di Bretschneider.

Escrivá, V. (1995). Cerámica común romana del Municipium Liria Edetanorum. Nuevas aportaciones al estudio de la cerámica alto-imperial en la Hispania Tarraconensis. En $\mathrm{X}$. Aquilué y M. Roca (Coors.). Ceràmica comuna romana d'època Alto-Imperial a la Península Ibèrica. Estat de la qüestió (pp. 167-186). Monografies Emporitanes VIII. Empúries: Museu d'Arqueologia de Catalunya.

Fernández García, Ma . I. (1992). Arqueología romana de la Provincia de Granada. Florentia Iliberritana, 2, 139-159.

Fernández García, Ma . I. (1997). Notas acerca de la terra sigillata hispanica del alfar del Carmen de la Muralla (Albaicín, Granada). Florentia Iliberritana, 8, 85-101.

Fernández García, Ma . I. (2004). Alfares y producciones cerámicas en la Provincia de Granada. Balance y perspectivas. En D. Bernal y L. Lagóstena (Eds.). Figlina Baeticae. Talleres alfareros y producciones cerámicas en la Bética romana (ss. II a.C.-VII d.C.) (pp. 195-238). BAR International Series 1266, 1. Oxford: British Archaeological Reports.

Fernández García, Mª I. (2013). Estructuras de comercialización. En $\mathrm{M}^{\mathrm{a}}$. I. Fernández (Coor.). Una aproximación a la Isturgi romana: el complejo alfarero de los Villares de Andújar, Jaén, España (pp. 129-153). Roma: Quasar.

Fernández García, Ma . I. (2015). La terra sigillata de origen bético: un camino por recorrer. En C. Fernández, A., Morillo y M. Zarzalejos (Eds.). Manual de cerámica romana II. Cerámicas romanas de época altoimperial en Hispania.
Importación y producción (pp. 233-296). Madrid: Museo Arqueológico de la Comunidad de Madrid.

Fernández García, Ma . I. y Ruiz Montes, P. (2005). Sigillata Hispánica de origen bético. En M. Roca y Mª I. Fernández (Coors). Introducción al Estudio de la cerámica romana. Una breve guía de referencia (pp. 139-182). Málaga: Universidad de Málaga.

García Vargas, E., Conlin, E. y Maestre, C. (2013). El horno altoimperial de Cortijo del Río (Marchena, Sevilla). Tipología y producciones cerámicas. En D. Bernal, L. C. Juan, M. Bustamante, J. J. Díaz y A. M. Sáez (Eds.). Hornos, talleres, y focos de producción alfarera en Hispania. I Congreso Internacional de la SECAH ex oficina Meridionalis (Cádiz, 2011) (pp. 257-294). Cádiz: Universidad de Cádiz.

Luezas, R. A. (2002). Cerámica común romana en La Rioja. Logroño: Instituto de Estudios Riojanos.

Moreno Pérez, A. S. y Orfila Pons, M. (2017). El complejo alfarero romano de Cartuja (Granada). Nuevos datos a partir de las actuaciones arqueológicas desarrolladas entre 20132015. Spal, 26, 187-210. DOI: http://dx.doi.org/10.12795/ spal.2017i26.08

Olcese, G. (2003). Ceramiche comuni a Roma e in area romana: produzione, circolazione e tecnología (tarda etá republicana - prima etá imperiale). Mantova: SAP Società Archeologica.

Orton C., Tyers P. y Vince A. (1997). La cerámica en arqueología. Barcelona: Crítica/Arqueología.

Peinado, Ma . V. (2010). Cerámicas comunes romanas en el Alto Guadalquivir: el alfar de los Villares de Andújar. (Tesis doctoral). Universidad de Granada. Granada. Recuperado de: http://hdl.handle.net/10481/5573

Peinado, Ma . V. (2013a). Cerámica común bética de pastas calcáreas. En $\mathrm{M}^{\mathrm{a}}$. I. Fernández (Coor.). Una aproximación a Istvrgi romana: el complejo alfarero de los Villares de Andújar, Jaén, España (pp. 247-269). Roma: Quasar.

Peinado, Ma. V. (2013b). Cerámica de cocina oxidante. En $\mathrm{M}^{\mathrm{a}}$. I. Fernández (Coor.). Una aproximación a Istvrgi romana: el complejo alfarero de los Villares de Andújar, Jaén, España (pp. 271-283). Roma: Quasar.

Peinado, Ma. V. (2013c). Cerámica de cocina reductora. En $\mathrm{M}^{\mathrm{a}}$. I. Fernández (Coor.). Una aproximación a Istvrgi romana: el complejo alfarero de los Villares de Andújar, Jaén, España (pp. 285-291). Roma: Quasar.

Py, M. y Adroher, A. M. (1991). Principes d'enregistrement du mobilier archéologique. En M. Py (Dir.). Système de gestion et d'exploitation de la documentation issue des fouilles de Lattes (pp. 83-101). Lattes: Lattara 4.

Rodríguez Aguilera, A., García Consuegra, J. M., Rodríguez Aguilera, J., Pérez Tovar, Ma. J. y Marín Díaz, P. (2014). La villa bajo imperial y tardoantigua de los Mondragones (Granada). Cuadernos de Prehistoria y Arqueología de la Universidad de Granada, 24, 459-496.

Román Punzón, J. M. y Fernández García, Mª I. (2012). El conjunto cerámico del Cerro de la Mora. En J. M. Román Punzón, J. A. Pachón, J. Carrasco y M. Pastor (Eds.). 
La Cuenca Alta del Genil en época romana: el Cerro de la Mora (Moraleda de Zafayona, Granada) (pp. 81-171). Sevilla: Junta de Andalucía.

Ruiz Montes, P., Fernández García, Mª I. y Rodríguez Ariza, Ma . O. (2010). Aportaciones a la configuración de las facies cerámicas de época romana en la Vega de Granada: la villa romana de Gabia. Antiqvitas, 22, 121-140.

Quercia, A. (2008). La ceramiche comuni di etá romana. En F. Filippi (Ed.). Horti et Sordes. Unoscavo alle falde del Gianicolo (pp. 141-176). Roma: Quasar.

Serrano, E. (1974). La cerámica romana de los hornos de Cartuja. (Tesis doctoral inédita). Universidad de Granada. Granada.

Serrano, E. (1975). La cerámica romana de los hornos de Cartuja (Granada). Cuadernos de Prehistoria de la Universidad de Granada, 1, 215-233.

Serrano, E. (1978). Cerámica común del alfar de Cartuja (Granada). Baetica, 1, 243-251.

Serrano, E. (1979). Sigillata hispánica de los hornos de Cartuja (Granada). Boletin del Seminario de Estudos de Arte y Arqueología, 42, 31-80.

Serrano, E. (1981). Cerámica de importación en el yacimiento romano de Cartuja (Granada). En Arqueología de Andalucía Oriental. Siete estudios (pp. 111-130). Málaga: Universidad de Málaga.

Serrano, E. (1995). Producciones de cerámicas comunes en la Bética. En X. Aquilué y M. Roca (Coors.). Ceràmica comuna romana d'època Alto-Imperial a la Península Ibèrica. Estat de la qüestió (pp. 227-249). Monografies Emporitanes VIII. Empúries: Museu d'Arqueologia de Catalunya.

Serrano, E. (1997). La producción cerámica de los talleres romanos de la Depresión de Antequera. en Figlinae Malacitanae. La producción de cerámica romana en los territorios malacitanos (pp. 217-232). Málaga: Universidad de Málaga.

Serrano, E. (1999). Centros productores de t.s.h. en las provincias de Granada y Málaga. En M. Roca y Ma . I. Fernández (Coors.). Terra Sigillata Hispanica. Centros de fabricación y producciones altoimperiales (pp. 137-167). Málaga: Universidad de Málaga.

Sotomayor, M. (1966). Alfar romano en Granada. En IX Congreso Nacional de Arqueología (Valladolid, 1965) (pp. 367-372). Zaragoza: Congresos Arqueológicos Nacionales.

Sotomayor, M. (1970). Siete hornos de cerámica romana en Granada con producción de sigillata. En XI Congreso $\mathrm{Na}$ cional de Arqueología (Mérida, 1968) (pp. 713-728). Zaragoza: Congresos Arqueológicos Nacionales.

Sotomayor, M. (1991). Consideraciones acerca del alfar romano de Cartuja. (Manuscrito inédito). Universidad de Granada. Granada.

Sotomayor, M. (1997). Algunas observaciones sobre hornos y excavaciones de alfares romanos. En Figlinae Malacitanae. La producción de cerámica romana en los territorios malacitanos (pp. 9-25). Málaga: Universidad de Málaga. 